\title{
Clinical characteristics of children with COVID-19: a rapid review and meta-analysis
}

\author{
Zijun Wang ${ }^{1 \#}$, Qi Zhou ${ }^{2 \#}$, Chenglin Wang ${ }^{3,4,5}$, Qianling Shi' ${ }^{2}$, Shuya $\mathrm{Lu}^{6,7}$, Yanfang $\mathrm{Ma}^{1}$, Xufei Luo ${ }^{8}$, \\ Yangqin Xun ${ }^{1}$, Weiguo Li ${ }^{3,4,5}$, Muna Baskota ${ }^{3,4,5}$, Yinmei Yang ${ }^{3,4,5}$, Hui Zhai ${ }^{3,4,5}$, Toshio Fukuoka ${ }^{9,10}$, \\ Hyeong Sik Ahn ${ }^{11,12}$, Myeong Soo Lee ${ }^{13,14}$, Zhengxiu Luo ${ }^{3,4,5}$, Enmei Liu ${ }^{3,4,5}$, Yaolong Chen ${ }^{1,15,16,17}$; \\ on behalf of COVID-19 Evidence and Recommendations Working Group
}

${ }^{1}$ Evidence-Based Medicine Center, School of Basic Medical Sciences, Lanzhou University, Lanzhou 730000, China; ${ }^{2}$ The First School of Clinical Medicine, Lanzhou University, Lanzhou 730000, China; ${ }^{3}$ Department of Respiratory Medicine, Children's Hospital of Chongqing Medical University, Chongqing 400014, China; ${ }^{4}$ National Clinical Research Center for Child Health and Disorders, Ministry of Education Key Laboratory of Child Development and Disorders, China International Science and Technology Cooperation Base of Child Development and Critical Disorders, Children's Hospital of Chongqing Medical University, Chongqing 400014, China; ${ }^{5}$ Chongqing Key Laboratory of Pediatrics, Chongqing 400014, China; ${ }^{6}$ Department of Pediatric, Sichuan Provincial People's Hospital, University of Electronic Science and Technology of China, Chengdu 611731, China; ${ }^{7}$ Chinese Academy of Sciences Sichuan Translational Medicine Research Hospital, Chengdu 610072, China; ${ }^{8}$ School of Public Health, Lanzhou University, Lanzhou 730000, China; ${ }^{9}$ Emergency and Critical Care Center, Department of General Medicine, Department of Research and Medical Education, Kurashiki Central Hospital, Kurashiki, Japan; ${ }^{10}$ Advisory Committee in Cochrane Japan, Tokyo, Japan; ${ }^{11}$ Department of Preventive Medicine, Korea University College of Medicine, Seoul, Korea; ${ }^{12}$ Korea Cochrane Center, Seoul, Korea; ${ }^{13}$ Korea Institute of Oriental Medicine, Daejeon, Korea; ${ }^{14}$ University of Science and Technology, Daejeon, Korea; ${ }^{15}$ Lanzhou University, an Affiliate of the Cochrane China Network, Lanzhou 730000, China; ${ }^{16}$ Chinese GRADE Center, Lanzhou 730000, China; ${ }^{17}$ Key Laboratory of Evidence Based Medicine and Knowledge Translation of Gansu Province, Lanzhou University, Lanzhou 730000, China

Contributions: (I) Conception and design: E Liu, Y Chen; (II) Administrative support: E Liu, Y Chen; (III) Provision of study materials or patients: E Liu; (IV) Collection and assembly of data: Z Wang, Q Zhou, C Wang, Q Shi, S Lu, Y Xun; (V) Data analysis and interpretation: Z Wang, Q Zhou, C Wang, Y Ma, X Luo; (VI) Manuscript writing: All authors; (VII) Final approval of manuscript: All authors.

\#These authors contributed equally to this work.

Correspondence to: Enmei Liu. Department of Respiratory Medicine, Children's Hospital of Chongqing Medical University, Chongqing 400014, China. Email: emliu186@126.com; Yaolong Chen. Evidence-Based Medicine Center, School of Basic Medical Sciences, Lanzhou University, Lanzhou 730000, China. Email: chenyaolong@1zu.edu.cn.

Background: Most guidelines on COVID-19 published so far include recommendations for patients regardless of age. Clinicians need a more accurate understanding of the clinical characteristics of children with COVID-19.

Methods: We searched studies reporting clinical characteristics in children with COVID-19 published until March 31, 2020. We screened the literature, extracted the data and evaluated the risk of bias and quality of evidence of the included studies. We combined some of the outcomes (symptoms) in a single-arm metaanalysis using a random-effects model.

Results: Our search retrieved 49 studies, including 25 case reports, 23 case series and one cohort study, with a total of 1,667 patients. Our meta-analysis showed that most children with COVID-19 have mild symptoms. Eighty-three percent of the children were within family clusters of cases, and $19 \%$ had no symptoms. At least 7\% with digestive symptoms. The main symptoms of children were fever [48\%, 95\% confidence interval (CI): 39\%, 56\%] and cough (39\%, 95\% CI: 30\%, 48\%). The lymphocyte count was below normal level in only 15\% (95\% CI: 8\%, 22\%) of children which is different from adult patients. $66 \%$ (95\% CI: $55 \%, 77 \%$ ) of children had abnormal findings in CT imaging.

Conclusions: Most children with COVID-19 have only mild symptoms, and many children are asymptomatic. Fever and cough are the most common symptoms in children. Vomiting and diarrhea were not common in children. The lymphocyte count is usually within the normal range in children. 
Keywords: Children; clinical characteristics; COVID-19; meta-analysis; rapid review

Submitted Apr 13, 2020. Accepted for publication Apr 26, 2020.

doi: 10.21037/atm-20-3302

View this article at: http://dx.doi.org/10.21037/atm-20-3302

\section{Introduction}

In December 2019, a previously unknown type of pneumonia broke out in Wuhan, China, which was later confirmed to be caused by a novel type of beta coronavirus, Severe Acute Respiratory Syndrome Coronavirus 2 (SARSCoV-2). In February 2020, the World Health Organization (WHO) officially named the disease as "Coronavirus Disease 2019 (COVID-19)" (1). Like MERS-CoV and SARS-CoV, SARS-CoV-2 can also be transmitted between humans (2-5). Since the occurrence of COVID-19 case $(6,7)$, the disease is spreading rapidly. WHO reassessed the potential impact of COVID-19 on global public health and subsequently declared COVID-19 as Public Health Emergency of International Concern (PHEIC) on January 30, 2020.

Research has proven that people of all ages are susceptible to SARS-CoV-2. The mean age of COVID-19 patients was 47 years, with $55 \%$ of the patients being between 15 and 49 years old. Only $9 \%$ of the patients were under 15 years old (8). For this reason, most of the guidelines published so far include recommendations for patients regardless of age, only a few recommendations are for children. Although the great majority of patients are adults, children's respiratory structural characteristics and immune response system differ essentially from those in adult (9-11), and the diagnostic criteria and management according to recommendations targeting adults may not be appropriate for children. Our study aims therefore to identify the clinical features of children with COVID-19, help clinicians to confirm and treat the suspected children as soon as possible, and provide support for the development of guidelines for COVID-19 in children. We present the following article in accordance with the PRISMA reporting checklist (available at http://dx.doi.org/10.21037/atm-203302).

\section{Methods}

\section{Search strategy}

We comprehensively searched the following electronic databases: Cochrane library, MEDLINE (via PubMed), Embase, Web of Science, China Biology Medicine disc (CBM), China National Knowledge Infrastructure (CNKI), and Wanfang Data from their inception until March 31, 2020 with the terms "2019-novel coronavirus", "SARSCoV-2", "COVID-19", "2019-nCoV”, "clinical features" and their derivatives. We also searched WHO, Chinese Center for Disease Control and Prevention (CCDC), National Health Commission of the People's Republic of China, USA National Institutes of Health Ongoing Trials Register (ClinicalTrials.gov), the ISRCTN registry, Google Scholar and the preprint servers medRxiv (https:// www.medrxiv.org/), bioRxiv (https://www.biorxiv.org/) and SSRN (https://www.ssrn.com/index.cfm/en/). In addition, we searched the reference lists of the identified studies for further potential studies. The full search strategy can be found in Supplementary File I.

\section{Inclusion and exclusion criteria}

We included studies on children (aged $<18$ years) with COVID-19 that report clinical features of patients, such as symptoms, signs, laboratory examinations and imaging manifestations. Diagnosis of COVID-19 was based on the Novel Coronavirus Pneumonia Prevention and Control Program (7th edition) issued by the National Health and Health Committee of China (12) and surveillance case definitions for human infection with novel coronavirus ( $\mathrm{nCoV}$ ) Interim guidance v2 issued by WHO (13). We excluded in vitro studies, Traditional Chinese Medicine studies, conference abstracts, comments, letters, and 
duplicates, and studies where we could not extract the data. We made no restrictions on language and publication status.

\section{Study selection}

Two reviewers ( $Z W$ and $C W$ ) selected the studies independently after first eliminating duplicates. The bibliographic software EndNote was used and any discrepancies were settled by discussion, consulting a third reviewer (QZ) if necessary. Before the formal selection, the reviewers searched a random sample of 50 citations. The reviewers screened first all titles and abstracts with the pre-defined criteria, and categorized the articles into three (eligible, not eligible, and unclear) groups. In the second step, full-texts of those potentially eligible or unclear studies were reviewed to identify the final inclusion. All the reasons for exclusion of ineligible studies were recorded, and the process of study selection was documented using a PRISMA flow diagram $(14,15)$.

\section{Data extraction}

Two reviewers (QS and SL) extracted the data independently with a standardized data collection form, including: (I) basic information (e.g., first author); (II) symptoms; (III) routine blood tests (e.g., leucocyte count); (IV) blood biochemistry [e.g., alanine aminotransferase (ALT)]; (V) coagulation function (e.g., activated partial thromboplastin time); (VI) imaging findings (e.g., abnormal imaging). For dichotomous outcomes, we abstracted the number of events and total participants per group. For continuous outcomes, we abstracted means, standard deviations (SD), and the number of total participants in per group. Outcomes with no events were reported, but these were excluded from the metaanalysis. If means and SD were not reported, we calculated them from the reported indicators (16). If data were missing or reported in an unusable way, we excluded the study from the meta-analysis and report the findings descriptively.

\section{Risk of bias assessment}

Two reviewers ( $Z W$ and $C W$ ) assess the risk of bias in each study independently. Discrepancies were settled by discussion, consulting a third reviewer (QZ) if necessary. For randomized controlled trials (RCTs), we will assess the risk of bias independently using Cochrane risk-of-bias tool (17). It consists of seven domains, for each, we will grade as "Low", "Unclear", and "High". For nonrandomized controlled trials (nRCTs), ROBINS-I tool will be used (18). It consists of seven domains, for each, we will grade as "Low risk", "Moderate risk", "Serious risk", "Critical risk", and "No information". For case-control and cohort studies, the Newcastle-Ottawa Scale will be used (19). It consists of eight domains, for each, we will grade with stars. The more stars, the lower the risk of bias. For cross-sectional studies, we use a methodology evaluation tool recommended by Agency for Healthcare Research and Quality (AHRQ) (20). This tool assesses the quality of bias according to 11 criteria. And each criterion is answered by "Yes", "No" or "Unsure". For case reports and case series, we used a methodology evaluation tool recommended by National Institute for Health and Care Excellence (NICE) (21). The risk of bias is evaluated according to eight criteria. The results were summarized by scoring method, for the "Yes" items, the score was 1 , and for the "No" items, the score was 0 . The higher the total score, the lower the risk of bias.

\section{Data synthesis}

We summarized the results of the studies including less than nine patients and did meta-analysis of included studies that have at least nine patients. For dichotomous outcomes, we did a meta-analysis of proportions, reporting the effect size (ES) with $95 \%$ confidence intervals (CI). For continuous outcomes, we did a metaanalysis of continuous variable, calculating the ES with 95\% CI. We described the results of the studies with patients that below nine. As clinical and methodological heterogeneity in the study design, characteristics of participants, interventions and outcome measures was expected, we used random-effects models (22). Two-sided $\mathrm{P}$ values $<0.05$ were considered statistically significant. Heterogeneity was defined as $\mathrm{P}$ values $<0.10$ and $\mathrm{I}^{2}>50 \%$. All analyses were performed in STATA version 14 .

\section{Quality of the evidence assessment}

Two reviewers (QZ and YX) assessed the quality of main evidence independently using the Grading of Recommendations Assessment, Development and Evaluation (GRADE) tool. We produced a "Summary of Findings" table using the GRADE pro software $(23,24)$. Direct evidence from RCTs is first set as high quality, and evidence from observational studies as low quality. Then initial quality can then be downgraded for five reasons (study 


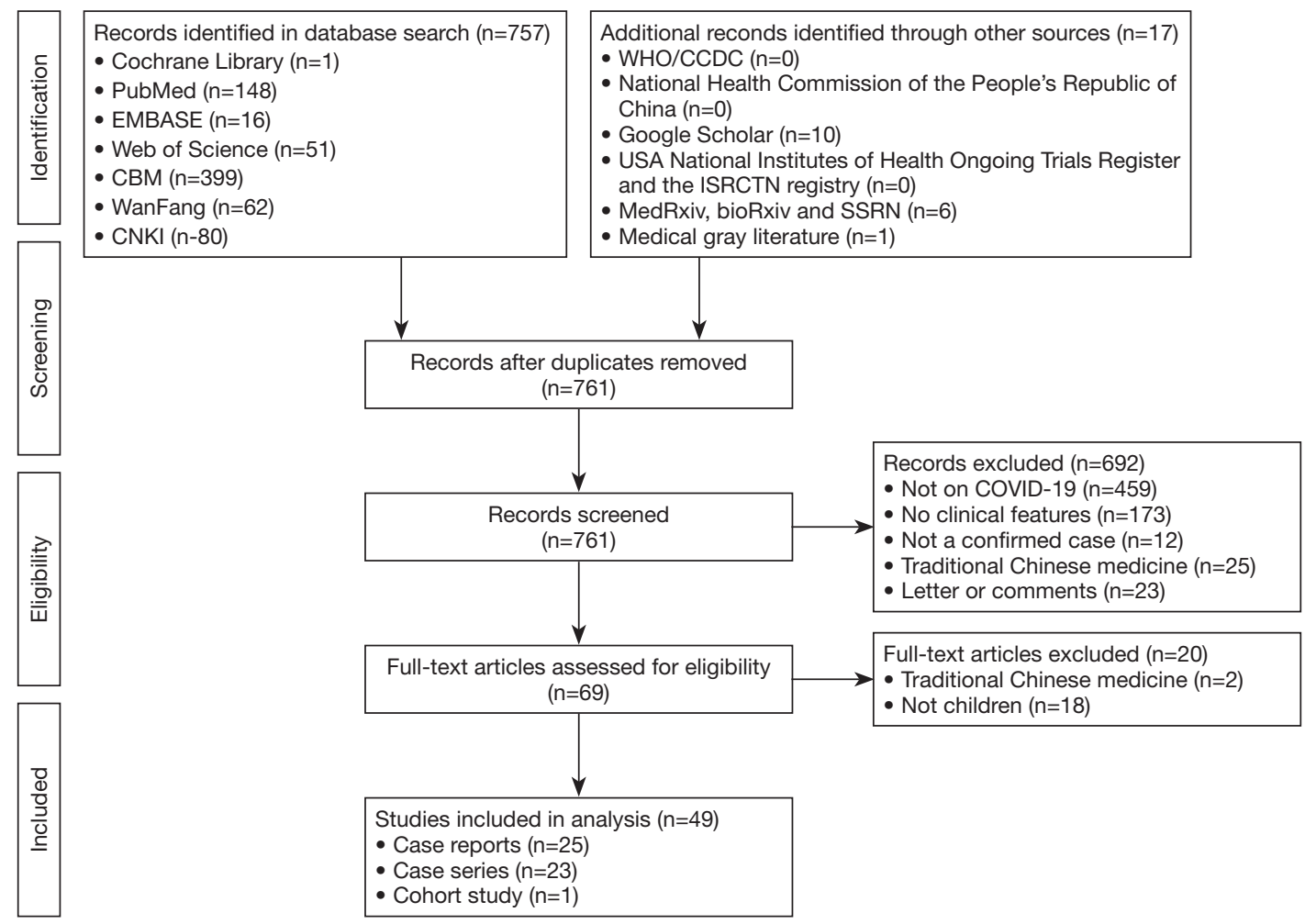

Figure 1 Flow diagram.

limitations, consistency of effect, imprecision, indirectness, and publication bias) and upgraded for three reasons (large magnitude of effect, dose-response relation and plausible confounders or biases) (25-30). Finally, the quality of main evidence can be classified as high, moderate, low, or very low, which reflects the extent to what we can be confident that the effect estimates are correct.

As COVID-19 is a PHEIC and the situation is evolving rapidly, our study was not registered in order to speed up the process (31).

\section{Results}

\section{Study selection and characteristics}

Our initial search retrieved 774 records (Figure 1). After removing duplicates, we screened the titles, abstracts and full texts, and 49 studies were finally included. The articles included 25 case reports, 23 case series and one cohort study. The studies included a total of 1,667 patients: 955 males and 712 females. Eighteen percent of children were aged less than 1 year. Most of the studies were carried out in China, including 17 studies from Hubei (Table 1). One study was from Singapore, one from Korea, one from Vietnam and one from Iran. The results on risk of bias are reported in Supplementary File II, and quality of the evidence in Supplementary File III.

\section{Symptoms and imaging results}

All of the included studies reported the symptoms of children with COVID-19. The results showed that $83 \%$ (95\% CI: $78 \%, 88 \%$ ) of the cases had likely acquired the infection from their family members with COVID-19. Ninety-four percent (95\% CI: 90\%, 98\%) of children were mild cases and 3\% (95\% CI: 2\%, 4\%) were severe case. Among the children with severe symptoms that reported symptom clearly, 9 children have comorbidity, 10 children have gastrointestinal symptoms and 4 children have concurrent infection. Only two children were dead that has been reported in our included studies $(46,65)$. The main symptoms were fever [48\% (95\% CI: 39\%, 56\%)], cough [39\% (95\% CI: 30\%, 48\%)]. Thirty percent (95\% CI: $18 \%$, $42 \%)$ of children had both cough and fever. Seven percent (95\% CI: 5\%, 9\%) and 6\% (95\% CI: 4\%, 9\%) of cases had 
Table 1 Characteristics of included studies

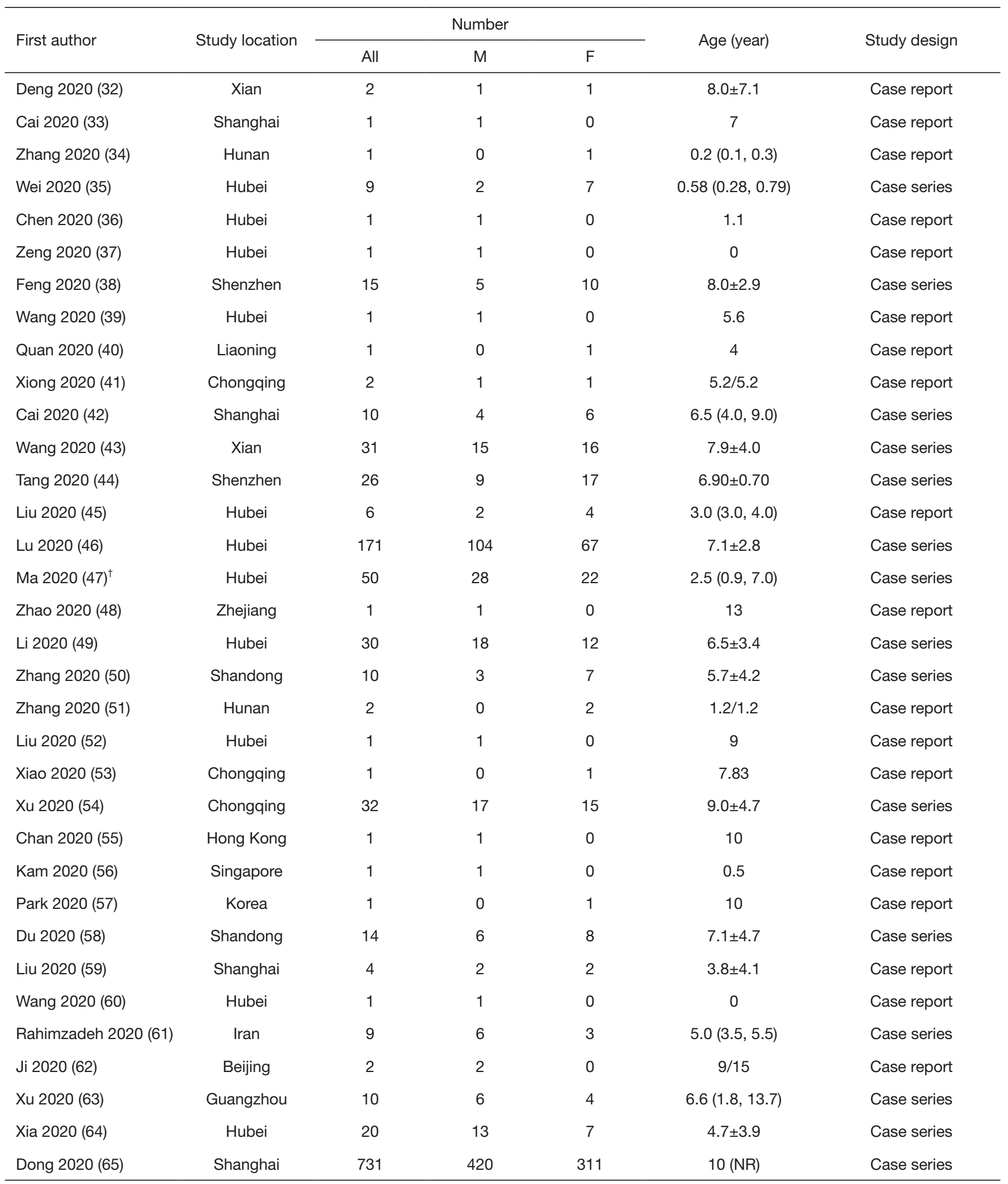

Table 1 (continued) 
Table 1 (continued)

\begin{tabular}{|c|c|c|c|c|c|c|}
\hline First author & Study location & \multicolumn{3}{|c|}{ Number } & Age (year) & Study design \\
\hline Xing 2020 (66) & Hong Kong & 3 & 2 & 1 & $1.5 / 2.5 / 3.6$ & Case report \\
\hline Yu 2020 (67) & Hubei & 82 & 51 & 31 & NR [0-16] & Case series \\
\hline Liu 2020 (68) & Hubei & 91 & 56 & 35 & NA & Case series \\
\hline Qian 2020 (70) & Zhejiang & 2 & 0 & 2 & 1.1 & Case report \\
\hline Qiu 2020 (71) & Zhejiang & 36 & 23 & 13 & $8.3 \pm 3.5$ & Cohort study \\
\hline Zhang 2020 (72) & Hubei & 25 & 14 & 11 & $3.0(2.0,9.0)$ & Case series \\
\hline Sun 2020 (73) & Hubei & 8 & 6 & 2 & $5.0(1.0,13.7)$ & Case report \\
\hline Su 2020 (76) & Shandong & 9 & 3 & 6 & $3.6(1.8,6.8)$ & Case series \\
\hline Le 2020 (77) & Vietnam & 1 & 0 & 1 & 0.3 & Case report \\
\hline Zhong 2020 (78) & Hunan & 9 & 4 & 5 & $8(1.5,10.0)$ & Case series \\
\hline Yang 2020 (79) & Shandong & 10 & 3 & 7 & $4(2,8)$ & Case series \\
\hline Tang 2020 (80) & Zhejiang & 1 & 1 & 0 & 10 & Case report \\
\hline
\end{tabular}

Ages were reported either as mean \pm SD, or median (interquartile range), or single year. ${ }^{\dagger}$, This article once has been retracted and republished by SSRN, now the data was updated with the new article. SD, standard deviation; NR, not report; NA, not applicable.

diarrhea and nausea/vomiting. The proportion of children with more than one symptom was $35 \%$ (95\% CI: $21 \%$, $48 \%$ ), and $19 \%$ (95\% CI: $14 \%, 23 \%$ ) of all children were asymptomatic.

Forty-two studies reported the imaging features of children with COVID-19, including 19 case series and 23 case reports. Sixty-six percent (95\% CI: 55\%, 77\%) had abnormal imaging. Thirty-five percent (95\% CI: $26 \%$, $44 \%$ ) of children had ground-glass opacity.

More information can be found in Table 2 and Supplementary File IV.

\section{Laboratory results}

Seventeen case series reported the results of routine blood tests. The mean leucocyte count in children was $6.25 \times 10^{9} / \mathrm{L}$ (95\% CI: 5.97, 6.54). Fifteen percent (95\% CI: $4 \%, 26 \%)$ of cases had leucocyte count above the normal range and $28 \%$ (95\% CI: $17 \%, 38 \%$ ) of cases below the normal range. The mean lymphocyte count in children was
$2.84 \times 10^{9} / \mathrm{L}$ (95\% CI: $\left.2.55,3.13\right)$. Lymphocyte count was elevated in $41 \%$ (95\% CI: $2 \%, 80 \%)$ and below normal in $15 \%$ (95\% CI: $8 \%, 22 \%$ ) of children.

Eighteen case series reported the results of blood biochemistry tests. The mean value of ALT was 20.46 U/L (95\% CI: 14.51, 26.41), and 11\% (95\% CI: 8\%, $14 \%)$ of cases had elevated ALT values. The mean value of aspartate aminotransferase (AST) was $32.04 \mathrm{U} / \mathrm{L}$ (95\% CI: $30.25,33.83$ ), and $15 \%$ (95\% CI: $9 \%, 21 \%)$ of cases had elevated AST values. The mean value of C-reactive protein (CRP) was $5.05 \mathrm{mg} / \mathrm{L}$ (95\% CI: 1.86, 8.24), and CRP was elevated in $22 \%$ (95\% CI: $15 \%, 28 \%$ ) of the children.

Nine case series reported coagulation function test, the mean value of $\mathrm{D}$-dimer was $0.33 \mathrm{mg} / \mathrm{L}$ (95\% CI: $0.17,0.49)$ in studies of children with COVID-19. Fifteen percent (95\% CI: $7 \%, 22 \%$ ) of cases above the normal range of D-dimer value.

More information can be found in Table 3 and Supplementary IV. 
Table 2 Symptoms and imaging results of patients with COVID-19

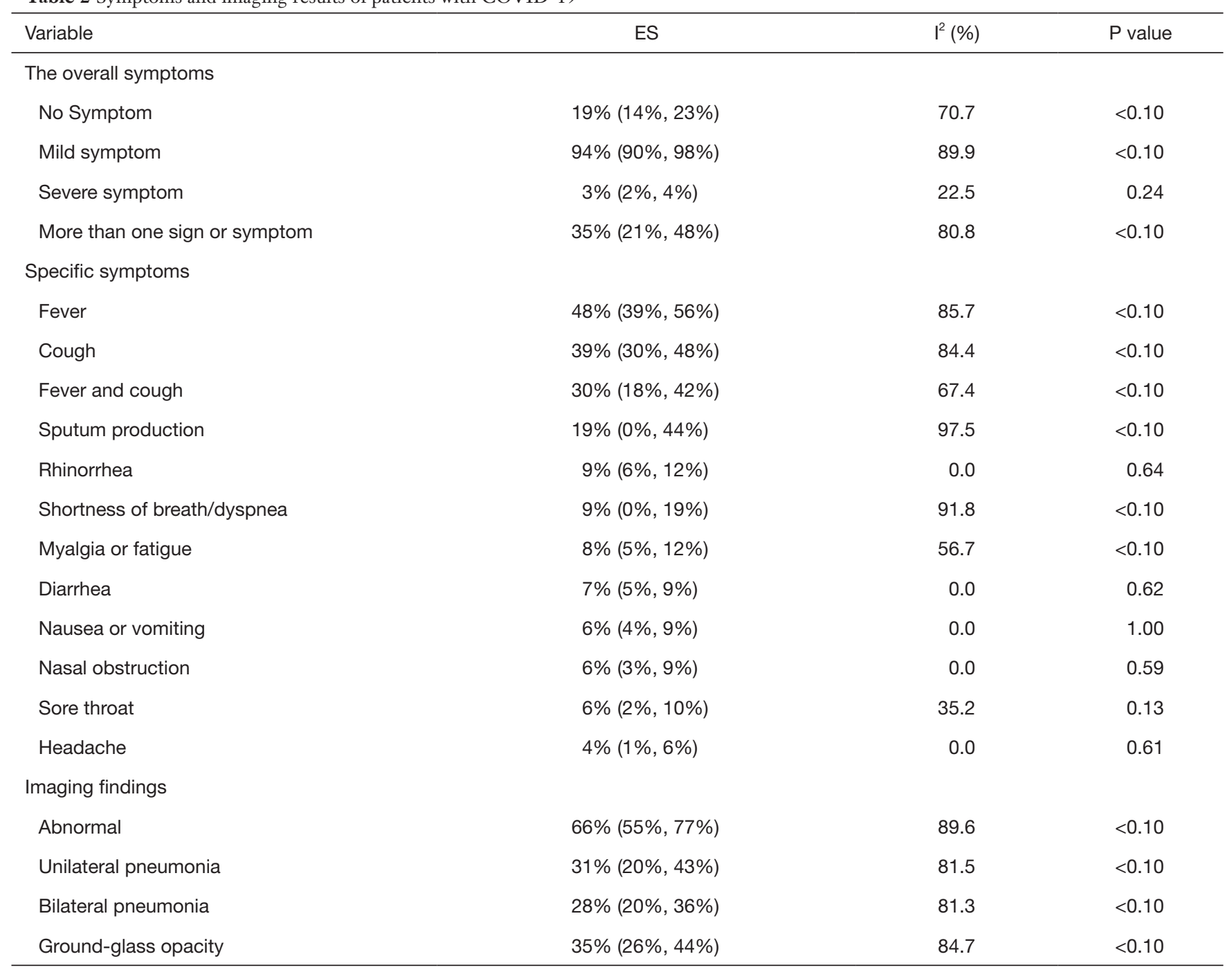

ES, effect size.

\section{Discussion}

\section{Principal findings}

Children had on average milder symptoms, with many children having even no symptoms. Most children infected with COVID-19 were exposed through family clusters. About half of children present with fever or cough, and about one-third of children with both fever and cough. Only a small minority of children had vomiting or diarrhea as initial symptoms. Leucocyte and lymphocyte counts are often in normal or above the normal range in children with COVID-19. Abnormalities in CT imaging were found in more than half of the children, the most common being ground-glass opacity in unilateral lung.
The course of COVID-19 in children can be characterized by mild illness and no symptoms. According to a study by the CCDC, as of February 11, 2020, $81 \%$ of all patients with COVID-19 showed only mild symptoms (81). However, although the disease was less severe in the majority of adults (51-74\%) (82-84), 26-32\% of adults were still committed to ICU, and had often basic diseases such as hypertension or diabetes (85-87). In contrast, we found only $3 \%$ report of children with severe illness. The CCDC also pointed out that 889 (1\%) patients with COVID-19 were asymptomatic (81); in our study, about $19 \%$ of children were completely asymptomatic, which is higher than the average level of the whole patient significantly. A study of asymptomatic infections with 
Table 3 Laboratory results of children with COVID-19

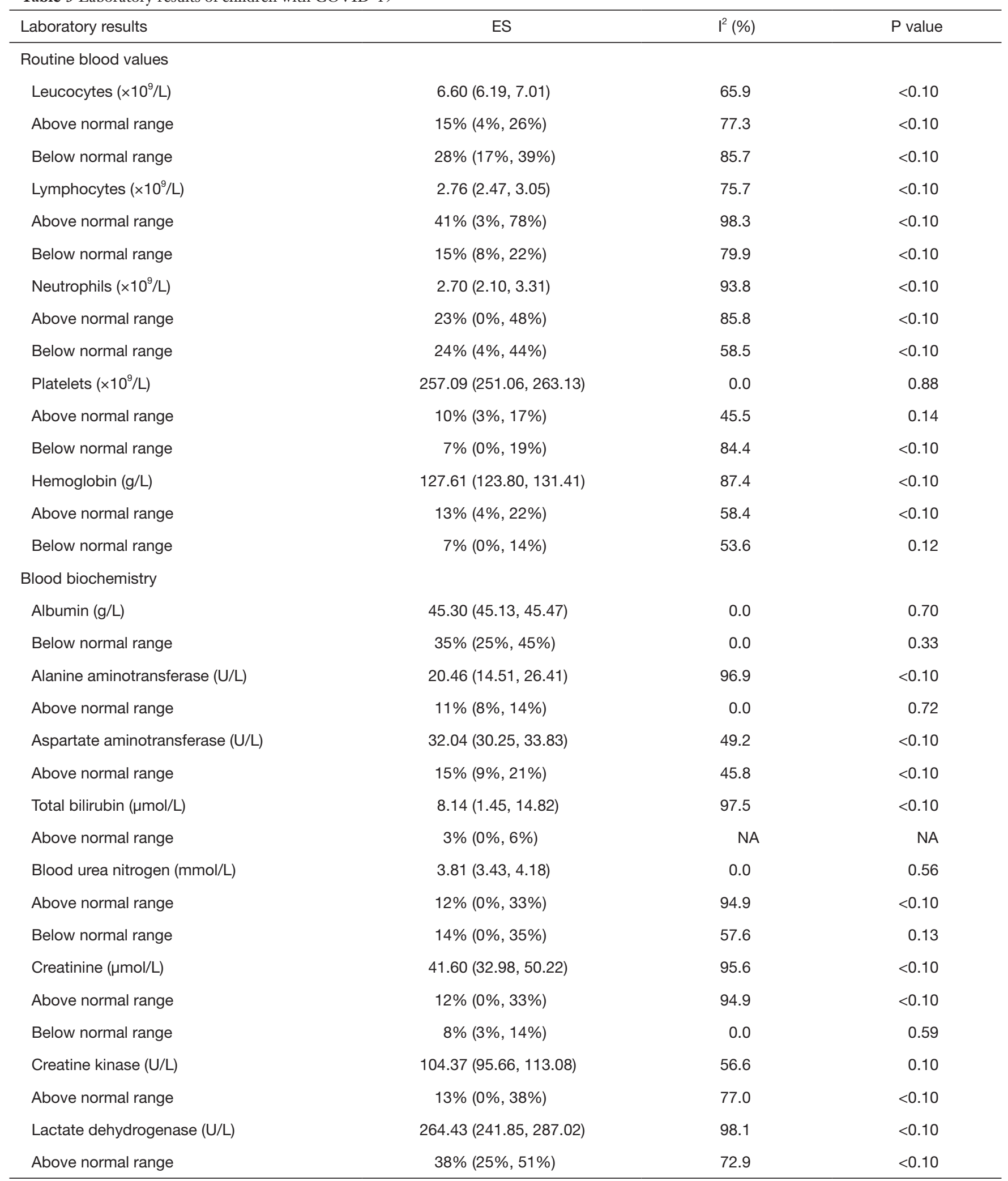

Table 3 (continued) 
Table 3 (continued)

\begin{tabular}{|c|c|c|c|}
\hline Laboratory results & ES & $\mathrm{I}^{2}(\%)$ & $P$ value \\
\hline Myoglobin ( $\mu \mathrm{g} / \mathrm{L})$ & $15.33(11.18,19.48)$ & NA & NA \\
\hline Procalcitonin (g/L) & $0.06(0.00,0.16)$ & 0.0 & 1.00 \\
\hline Above normal range & $44 \%(20 \%, 69 \%)$ & 98.0 & $<0.10$ \\
\hline Above normal range & $22 \%(15 \%, 29 \%)$ & 71.3 & $<0.10$ \\
\hline \multicolumn{4}{|l|}{ Coagulation function } \\
\hline Activated partial thromboplastin time (s) & $37.59(28.69,46.48)$ & 96.4 & $<0.10$ \\
\hline Increased & $11 \%(5 \%, 18 \%)$ & 0.0 & 0.72 \\
\hline Increased & $2 \%(0 \%, 4 \%)$ & 0.0 & 0.42 \\
\hline Decreased & $2 \%(0 \%, 6 \%)$ & NA & NA \\
\hline D-dimer (mg/L) & $0.33(0.17,0.49)$ & 0.0 & 0.98 \\
\hline Increased & $15 \%(7 \%, 22 \%)$ & 38.4 & 0.17 \\
\hline
\end{tabular}

ES, effect size; NA, not applicable.

COVID-19 also showed that $29.2 \%$ of cases showed normal CT image and had no symptoms during hospitalization. What's more, these cases were younger (median age: 14.0 years; $\mathrm{P}=0.012$ ) than the rest (88). Of children with COVID-19, $83 \%$ had other family members infected. The majority of asymptomatic children in family clusters were confirmed after a positive nucleic acid test, which was conducted because of the close contact to infected family members. It seems that family cluster in children were more likely to be tested than adults. So, we suspect whether asymptomatic children are really asymptomatic or are still in the incubation period. Another explanation could be that only symptomatic cases transmit; So, adults without symptoms are seldom diagnosed, while children without symptoms (who had not that many any other contacts during the holiday season than their family members) get diagnosed anyway because of the obvious exposure.

The diagnosis of suspected cases in children needs comprehensive consideration. Fever and cough were the main symptoms in patients with COVID-19, which is reported by the most of current guidelines and recommendations (12,89-92). Although fever and cough also the first two symptom of children. When compared with adults, fever and cough occurred only in $48 \%$ and $39 \%$ of children, respectively. The rates of fever and cough in adults are up to $98 \%$ (87) and $87 \%$ (83), which indicates that fever and cough in children are not as common as in adults. Compared with children infected with SARS, MERS and other viral diseases $(93,94)$, there are no specific symptoms in children with COVID-19 that could help to diagnose the disease accurately. Therefore, detection methods are particularly important for the diagnosis of COVID-19. Chinese National Health Commission also pointed out that fever and/or respiratory symptoms, imaging features indicating of pneumonia, leukocyte and lymphocyte counts characteristics in the early stage, and epidemiological history should be comprehensively used to determine suspected cases. After that, RT-PCR, sequencing or specific antibody were used to make a definite diagnosis (12).

Attention should be paid to the children with COVID-19 who start with gastrointestinal symptoms. Although gastrointestinal symptoms such as nausea, vomiting and diarrhea are less common in children with COVID-19, recent studies have SARS-CoV-2 in the feces of patients $(95,96)$ and a study showed that some children persistently tested positive on rectal swabs even after nasopharyngeal testing was negative, raising the possibility of fecal-oral 
transmission (63). According to one study, diarrhea was the first symptom in three out of 31 children (87). Moreover, three of the eight children with severe cases of COVID-19 that reported symptom clearly had gastrointestinal symptoms, one of them started with gastrointestinal symptoms, without any obvious respiratory tract infection in the early stage (36). In addition, comorbidity cannot be ignored either. Our results showed that half of these eight children with severe cases had other diseases, including two with intussusception and one of them was dead (46). Similarly, a study of children with MERS also suggest that serious illness can occur in children with underlying disease (94). Although there is no evidence that gastrointestinal symptoms and comorbidity in children are related to the severity of the disease, clinicians should pay attention to the gastrointestinal symptoms and comorbidity in the process of diagnosing children with COVID-19 and apply real-time monitoring and protection.

Abnormal CT imaging was less common in children with COVID-19 than adults, but the imaging findings were similar in children and adults. Unilateral pneumonia is common in children with COVID-19, and the main change in imaging is ground-glass opacity. However, bilateral pneumonia is more common in adults, and the main change in imaging is also ground-glass opacity $(85,86)$. One guideline (92) pointed out that there were multiple small patch shadows and interstitial changes in the early stages of the disease in adults, especially in the extrapulmonary zone in chest imaging. Furthermore, multiple groundglass opacity or infiltrative shadows may develop in both lungs. In severe cases, pulmonary consolidation may occur, and pleural effusion is rare. An analysis of CT features in children with COVID-19 showed that in 15 cases, inflammatory infiltration was found in the chest CT imaging during initial diagnosis and reexamination. Most inflammatory infiltrations were manifested as small nodular ground-glass opacities, and multiple lobe segments were less involved. Multiple lobe segments were involved in only one case, and the imaging changes were not typical in the advanced stage as well (38). These findings suggest that pulmonary inflammation in children is mild and localized.

The results of laboratory tests of children with COVID-19 were more often within the normal range than those of adults. The leukocyte count of children with COVID-19 was usually normal or below the normal range. The lymphocyte count was generally normal or above the normal range, and only $15 \%$ of cases were below the normal range. While for adults, the leukocyte count was usually normal or above the normal range, and the lymphocyte count were mostly below the normal range (35-63\%) $(85,86)$. It can be seen that there were significant differences in routine blood values between adults and children. However, some published COVID-19 guidelines and consensus for children consider a reduction in lymphocyte count as one of the factors for diagnosing suspected cases (89-91). Our study demonstrates that guidelines for children should not be formulated in full accordance with adult standards, otherwise true cases may be missed. Other laboratory tests, including liver and renal function, CRP, procalcitonin (PCT) and coagulation tests, most indicators in children tend to be normal. Although $35 \%$ of children with COVID-19 had albumin below the normal range, 38\% of cases had lactate dehydrogenase above the normal range, and $22 \%$ of cases had CRP above the normal range, which were the most significant changes of children, the rate of changes was still much lower than in adults (86). This result suggests that majority of children with COVID-19 have laboratory results within the normal range, but close clinical monitoring should still be observed.

Most of the existing systematic reviews on characteristics of patients with COVID-19 are based on adult patients or patients regardless of age (97-102). Two of these compared the differences between children and adult patients $(97,98)$. Only one review reported the clinical characteristics of children with COVID-19 at present (103). All reviews that considered children had similar outcomes: for example, children had milder symptoms than adults, some children had no symptoms, and lymphopenia in children did not occur as often as in adults. But our rapid review has included 49 studies of children patients, which is more than most of these reviews together. In contrast to another systematic review of children with COVID-19 (103), we included studies not only China but also from other countries such as Singapore, which were published in Chinese and English. Moreover, we conducted a meta-analysis whereas the previous study only did a systematic literature review.

\section{Strengths and limitations}

This rapid review has several strengths. First, although this is not the first systemic review about the clinical characteristics of children with COVID-19, but is to our knowledge the first to combine the results with meta-analysis and GRADE evaluation of the quality of main evidence, which is of great importance for clinicians to diagnose and treat children rapidly. Second, our study points out the loopholes in some 
current guidance documents that suggest the diagnosis of suspected cases-also in children-based on the lymphocyte count. Third, as a rapid review, this study summarizes the latest published information on clinical cases, which provides relatively high-quality evidence for the formulation of clinical practice guidelines in the rapidly evolving public health emergency situation and helps policy-makers to make evidence-based decisions quickly (104).

Our study has also some limitations. First, due to the rapid fermentation of the public health emergency and new cases emerging continuously, the findings of this review may get outdates relatively soon. Second, cannot be sure if some cases were included in multiple studies. Third, at present, there is no unified definition for clinical classification of the severity of COVID-19, so we had to combine light, mild and moderate disease into one category (mild), while severe and critical cases were both considered as severe cases.

\section{Future implications}

The researchers should aim to conduct more targeted studies on COVID-19 in specific subpopulations. Policy makers should develop accurate guidelines for both children and adults. Clinical practitioners should pay attention on the specific characteristics of different patient populations to improve the accuracy of diagnosis and treatment.

\section{Conclusions}

Children with COVID-19 are more common to have only mild symptoms, and many children are even completely asymptomatic. Fever and cough are the main symptoms of COVID-19 in both children. Vomiting and diarrhea occurring less frequently in children. Ground-glass opacity is the most common CT imaging of children. Whereas adults tend to have elevated lymphocyte count at the beginning of the disease, in children the lymphocytes were usually within the normal range. As the characteristics of COVID-19 differ between adults and children in multiple ways, specific criteria for the diagnosis and treatment of COVID-19 in children are urgently needed.

\section{Acknowledgments}

We thank Janne Estill, Institute of Global Health of University of Geneva for providing guidance and comments for our review. We thank all the authors for their wonderful collaboration.
Funding: This work was supported by grants from National Clinical Research Center for Child Health and Disorders (Children's Hospital of Chongqing Medical University, Chongqing, China) (grant number NCRCCHD-2020EP-01) to EL; Special Fund for Key Research and Development Projects in Gansu Province in 2020, to YC; the Fourth Batch of "Special Project of Science and Technology for Emergency Response to COVID-19" of Chongqing Science and Technology Bureau, to EL; special funding for prevention and control of emergency of COVID-19 from Key Laboratory of Evidence Based Medicine and Knowledge Translation of Gansu Province (grant number No. GSEBMKT-2020YJ01), to YC; The Fundamental Research Funds for the Central Universities (lzujbky-2020-sp14), to YC.

\section{Footnote}

Reporting Checklist: The authors have completed the PRISMA reporting checklist. Available at http://dx.doi. org/10.21037/atm-20-3302

Conflicts of Interest: All authors have completed the ICMJE uniform disclosure form (available at http://dx.doi. org/10.21037/atm-20-3302). MSL serves as the unpaid editorial board member of Annals of Translational Medicine from Nov 2019 to Oct 2021. The other authors have no conflicts of interest to declare.

Ethical Statement: The authors are accountable for all aspects of the work in ensuring that questions related to the accuracy or integrity of any part of the work are appropriately investigated and resolved.

Open Access Statement: This is an Open Access article distributed in accordance with the Creative Commons Attribution-NonCommercial-NoDerivs 4.0 International License (CC BY-NC-ND 4.0), which permits the noncommercial replication and distribution of the article with the strict proviso that no changes or edits are made and the original work is properly cited (including links to both the formal publication through the relevant DOI and the license). See: https://creativecommons.org/licenses/by-nc-nd/4.0/.

\section{References}

1. World Health Organization. WHO Director-General's remarks at the media briefing on 2019-nCoV on 11 
February 2020. 2020. Available online: https://www.who. $\mathrm{int} / \mathrm{dg} / \mathrm{speeches} /$ detail/who-director-general-s-remarks-atthe-media-briefing-on-2019-ncov-on-11-february-2020

2. Zhu N, Zhang $\mathrm{D}$, Wang $\mathrm{W}$, et al. A novel coronavirus from patients with pneumonia in China, 2019. N Engl J Med 2020;382:727-33.

3. Lu R, Zhao X, Li J, et al. Genomic characterisation and epidemiology of 2019 novel coronavirus: implications for virus origins and receptor binding. Lancet 2020;395:565-74.

4. Li Q, Guan X, Wu P, et al. Early Transmission dynamics in Wuhan, China, of novel coronavirus-infected pneumonia. N Engl J Med 2020;382:1199-207.

5. Yu P, Zhu J, Zhang Z, et al. A familial cluster of infection associated with the 2019 novel coronavirus indicating potential person-to-person transmission during the incubation period. J Infect Dis 2020. doi: 10.1093/infdis/ jiaa077.

6. Lu H, Stratton CW, Tang YW. Outbreak of pneumonia of unknown etiology in Wuhan, China: The mystery and the miracle. J Med Virol 2020;92:401-2.

7. Bogoch II, Watts A, Thomas-Bachli A, et al. Potential for global spread of a novel coronavirus from China. J Travel Med 2020. doi: 10.1093/jtm/taaa011.

8. Wu J, Wu X, Zeng W, et al. Chest CT findings in patients with corona virus disease 2019 and its relationship with clinical features. Invest Radiol 2020;55:257-61.

9. Shen K, Yang Y, Wang T, et al. Diagnosis, treatment, and prevention of 2019 novel coronavirus infection in children: experts' consensus statement. World J Pediatr 2020. [Epub ahead of print].

10. Shen KL, Yang YH. Diagnosis and treatment of 2019 novel coronavirus infection in children: a pressing issue. World J Pediatr 2020. [Epub ahead of print].

11. Chen ZM, Fu JF, Shu Q. New coronavirus: new challenges for pediatricians. World J Pediatr 2020. [Epub ahead of print].

12. National Health Commission of the People's Republic of China. The novel coronavirus pneumonia diagnosis and treatment plan (trial version 7). 2020. Available online: http://www.nhc.gov.cn/yzygj/s7653p/202003/46c9294a7df e4cef80dc7f5912eb1989.shtml

13. World Health Organization. Global Surveillance for human infection with coronavirus disease (COVID-19). 2020. Available online: https://www.who.int/publicationsdetail/global-surveillance-for-human-infection-withnovel-coronavirus-(2019-ncov)

14. Liberati A, Altman DG, Tetzlaff J, et al. The PRISMA statement for reporting systematic reviews and metaanalyses of studies that evaluate health care interventions: explanation and elaboration. PLoS Med 2009;6:e1000100.

15. Tian J, Zhang J, Ge L, et al. The methodological and reporting quality of systematic reviews from China and the USA are similar. J Clin Epidemiol 2017;85:50-8.

16. Wan X, Wang W, Liu J, et al. Estimating the sample mean and standard deviation from the sample size, median, range and/or interquartile range. BMC Med Res Methodol 2014;14:135.

17. Higgins JPT, Altman DG, Gotzsche PC, et al. The Cochrane Collaboration's tool for assessing risk of bias in randomised trials. BMJ 2011;343:d5928.

18. Sterne JAC, Hernán MA, Reeves BC, et al. ROBINS-I: a tool for assessing risk of bias in non-randomised studies of interventions. BMJ 2016;355:i4919.

19. Wells G, Shea B, O'Connell D, et al. NewcastleOttawa Quality Assessment Scale--Case Control Studies. Available online: http://www.ohri.ca/programs/clinical_ epidemiology/oxford.asp

20. Rostom A, Dubé C, Cranney A, et al. Celiac Disease. Appendix D. Quality Assessment Forms. Rockville: Agency for Healthcare Research and Quality (US), 2004.

21. National Institute for Health and Care Excellence. Appendix 4. Quality assessment for Case series. 2013. Available online: https://www.nice.org.uk/guidance/cg3/ documents/appendix-4-quality-of-case-series-form2

22. DerSimonian R, Kacker R. Random-effects model for meta-analysis of clinical trials: an update. Contemp Clin Trials 2007;28:105-14.

23. Guyatt G, Oxman AD, Akl EA, et al. GRADE guidelines: 1 . Introduction-GRADE evidence profiles and summary of findings tables. J Clin Epidemiol 2011;64:383-94.

24. Norris SL, Meerpohl JJ, Akl EA, et al. The skills and experience of GRADE methodologists can be assessed with a simple tool. J Clin Epidemiol 2016;79:150-8.e1.

25. Guyatt GH, Oxman AD, Vist G, et al. GRADE guidelines: 4. Rating the quality of evidence--study limitations (risk of bias). J Clin Epidemiol 2011;64:407-15.

26. Guyatt GH, Oxman AD, Montori V, et al. GRADE guidelines: 5 . Rating the quality of evidence--publication bias. J Clin Epidemiol 2011;64:1277-82.

27. Guyatt GH, Oxman AD, Kunz R, et al. GRADE guidelines 6. Rating the quality of evidence--imprecision. J Clin Epidemiol 2011;64:1283-93.

28. Guyatt GH, Oxman AD, Kunz R, et al. GRADE guidelines: 7. Rating the quality of evidence--inconsistency. J Clin Epidemiol 2011;64:1294-302. 
29. Guyatt GH, Oxman AD, Kunz R, et al. GRADE guidelines: 8. Rating the quality of evidence--indirectness. J Clin Epidemiol 2011;64:1303-10.

30. Guyatt GH, Oxman AD, Sultan S, et al. GRADE guidelines: 9. Rating up the quality of evidence. J Clin Epidemiol 2011;64:1311-6.

31. Ge L, Tian JH, Li YN, et al. Association between prospective registration and overall reporting and methodological quality of systematic reviews: a metaepidemiological study. J Clin Epidemiol 2018;93:45-55.

32. Deng H, Zhang Y, Wang Y, et al. Two cases of novel coronavirus infection in children. Pediatr Emerg Med 2020;27:81-3.

33. Cai JH, Wang XS, Ge YL, et al. First case of 2019 novel coronavirus infection in children in Shanghai. Zhonghua Er Ke Za Zhi 2020;58:86-7.

34. Zhang YH, Lin DJ, Xiao MF, et al. 2019-novel coronavirus infection in a three-month-old baby. Zhonghua Er Ke Za Zhi 2020;58:182-4.

35. Wei M, Yuan J, Liu Y, et al. Novel Coronavirus Infection in Hospitalized Infants Under 1 Year of Age in China. JAMA 2020;323:1313-4.

36. Chen F, Liu ZS, Zhang FR, et al. First case of severe childhood novel coronavirus pneumonia in China. Zhonghua Er Ke Za Zhi 2020;58:179-82.

37. Zeng LK, Tao XW, Yuan WH, et al. First case of neonate infected with novel coronavirus pneumonia in China. Zhonghua Er Ke Za Zhi 2020;58:E009.

38. Feng K, Yun YX, Wang XF, et al. Analysis of CT features of 15 Children with 2019 novel coronavirus infection. Zhonghua Er Ke Za Zhi 2020;58:275-8.

39. Wang H, Duan X, Yan X, et al. A case of novel coronavirus pneumonia complicated with acute appendicitis in children. Chin J Pediatr Surg 2020. doi: 10.1101/2020.04.13.20064352.

40. Quan S, Li X, Ding D, et al. A case of novel coronavirus infection in children in Liaoning. Pediatr Emerg Med 2020. doi: 10.3760/cma.j.issn.1673-4912.2020.0005.

41. Xiong D, Jiang J, Feng Y, et al. Novel coronavirus pneumonia in children: a report of two cases. Pediatr Emerg Med 2020. doi: 10.3760/cma. j.issn.1673-4912.2020.0002.

42. Cai J, Xu J, Lin D, et al. A case series of children with 2019 novel coronavirus infection: clinical and epidemiological features. Clin Infect Dis 2020;58:E269.

43. Wang D, Ju XL, Xie F, et al. Clinical analysis of 31 cases of 2019 novel coronavirus infection in children from six provinces (autonomous region) of Northern China.
Zhonghua Er Ke Za Zhi 2020;58:E011.

44. Tang $\mathrm{A}, \mathrm{Xu} W$, Shen $M$, et al. A retrospective study of the clinical characteristics of COVID-19 infection in 26 children. medRxiv 2020. doi: 10.1101/2020.03.08.20029710.

45. Liu W, Zhang Q, Chen J, et al. Detection of Covid-19 in Children in Early January 2020 in Wuhan, China. N Engl J Med 2020;382:1370-1.

46. Lu X, Zhang L, Du H, et al. SARS-CoV-2 Infection in Children. N Engl J Med 2020;382:1663-5.

47. Ma H, Hu J, Tian J, et al. Visualizing the novel coronavirus (COVID-19) in children: What we learn from patients at Wuhan Children's Hospital. SSRN 2020. Available online: https://papers.ssrn.com/sol3/papers.cfm?abstract_ id $=3556676$

48. Zhao R, Shen X, Xu K, et al. A case of 2019 novel coronavirus infection in children. Zhejiang Medical Journal 2020;42:305-6.

49. Li Q, Peng X, Sun Z, et al. Clinical and imaging characteristics of children with corona virus disease 2019 (COVID-19). Radiol Practice 2020;35:277-80.

50. Zhang X, Ma Y, Xiao J, et al. Clinical characteristics of novel coronavirus pneumonia in children in Jinan. Journal of Shandong University (Health Sciences) 2020;58:62-4.

51. Zhang GX, Zhang AM, Huang L, et al. Twin girls infected with SARS-CoV-2. Zhongguo Dang Dai Er Ke Za Zhi 2020;22:221-5.

52. Liu M, Wan X, Tu X, et al. Family cluster of child SARSCoV-2 infections: a case report. Medical Journal of Wuhan University 2020;3:362-5.

53. Xiao K, Shui L, Pang X, et al. The clinical features of the 143 patients with COVID-19 in North-East of Chongqing. Journal of Third Military Medical University 2020. doi: 10.16016/j.1000-5404.202002097.

54. Xu H, Liu E, Xie J, et al. A follow-up study of children infected with SARS-CoV-2 from Western China. medRXiv 2020. doi: 10.1101/2020.04.20.20073288.

55. Chan JF, Yuan S, Kok KH, et al. A familial cluster of pneumonia associated with the 2019 novel coronavirus indicating person-to-person transmission: a study of a family cluster. Lancet 2020;395:514-23.

56. Kam KQ, Yung CF, Cui L, et al. A Well Infant with Coronavirus Disease 2019 (COVID-19) with High Viral Load. Clin Infect Dis 2020. [Epub ahead of print].

57. Park JY, Han MS, Park KU, et al. First Pediatric Case of Coronavirus Disease 2019 in Korea. J Korean Med Sci 2020;35:e124.

58. Du W, Yu J, Wang H, et al. Clinical characteristics of 
COVID-19 in children compared with adults outside of Hubei Province in China. SSRN 2020. doi: 10.2139/ ssrn.3546097.

59. Liu H, Liu F, Li J, et al. Clinical and CT imaging features of the COVID-19 pneumonia: Focus on pregnant women and children. J Infect J Infect 2020;80:e7-13.

60. Wang S, Guo L, Chen L, et al. A case report of neonatal COVID-19 infection in China. Clin Infect Dis 2020. [Epub ahead of print].

61. Rahimzadeh G, Ekrami NM, Kadkhodaei EF, et al. COVID-19 Infection in Iranian Children: A Case Series of 9 Patients. Journal of Pediatrics Review 2020;8:139-44.

62. Ji LN, Chao S, Wang Y, et al. Clinical features of pediatric patients with COVID-19: a report of two family cluster cases. World J Pediatr 2020. [Epub ahead of print].

63. Xu Y, Li X, Zhu B, et al. Characteristics of pediatric SARS$\mathrm{CoV}-2$ infection and potential evidence for persistent fecal viral shedding. Nat Med 2020;26:502-5.

64. Xia W, Shao J, Guo Y, et al. Clinical and CT features in pediatric patients with COVID-19 infection: Different points from adults. Pediatr Pulmonol 2020;55:1169-74.

65. Dong Y, Mo X, Hu Y, et al. Epidemiological characteristics of 2143 pediatric patients with 2019 coronavirus disease in China. Pediatrics 2020. doi: 10.1542/peds.2020-0702.

66. Xing $\mathrm{Y}, \mathrm{Ni} W, \mathrm{Wu} Q$, et al. Prolonged presence of SARS$\mathrm{CoV}-2$ in feces of pediatric patients during the convalescent phase. medRxiv 2020. doi: 10.1101/2020.03.11.20033159.

67. Yu H, Cai Q, Dai X, et al. The clinical and epidemiological features and hints of 82 confirmed COVID-19 pediatric cases aged 0-16 in Wuhan, China. medRxiv 2020. doi: 10.1101/2020.03.15.20036319.

68. Liu J, Luo W, Deng Z, et al. Clinical and epidemiological characteristics of 91 children conformed with COVID-19. Chin J Nosocomiol 2020;30:1645-9.

69. Ma YL, Xia SY, Wang M, et al. Clinical features of children with SARS-CoV-2 infection: an analysis of 115 cases. Zhongguo Dang Dai Er Ke Za Zhi 2020;22:290-3.

70. Qian G, Yang N, Ma AHY, et al. A COVID-19 Transmission within a family cluster by presymptomatic infectors in China. Clin Infect Dis 2020. [Epub ahead of print].

71. Qiu H, Wu J, Hong L, et al. Clinical and epidemiological features of 36 children with coronavirus disease 2019 (COVID-19) in Zhejiang, China: an observational cohort study. Lancet Infect Dis 2020. [Epub ahead of print].

72. Zheng F, Liao C, Fan Q, et al. Clinical characteristics of children with coronavirus disease 2019 in Hubei, China. Curr Med Sci 2020;40:275-80.
73. Sun D, Li H, Lu X, et al. Clinical features of severe pediatric patients with coronavirus disease 2019 in Wuhan: a single center's observational study. World J Pediatr 2020. [Epub ahead of print].

74. Dong X, Cao Y, Lu X, et al. Eleven faces of coronavirus disease 2019. Allergy 2020. [Epub ahead of print].

75. Wu Q, Xing Y, Shi L, et al. Epidemiological and clinical characteristics of children with coronavirus disease 2019. medRxiv 2020. doi: 10.1101/2020.03.19.20027078.

76. Su L, Ma X, Yu H, et al. The different clinical characteristics of corona virus disease cases between children and their families in China - the character of children with COVID-19. Emerg Microbes Infect 2020;9:707-13.

77. Le HT, Nguyen LV, Tran DM, et al. The first infant case of COVID-19 acquired from a secondary transmission in Vietnam. Lancet Child Adolesc Health 2020;4:405-6.

78. Zhong Z, Xie X, Huang W, et al. Chest CT findings and clinical features of coronavirus disease 2019 in children. Zhong Nan Da Xue Xue Bao Yi Xue Ban 2020;45:236-42.

79. Yang L, Li Z, Xu H, et al. Epidemiological and clinical characteristics of 10 children with coronavirus disease (COVID-19) in Jinan City. Journal of Shandong University (Health Sciences) 2020;58:36-9.

80. Tang A, Tong ZD, Wang HL, et al. Detection of Novel Coronavirus by RT-PCR in Stool Specimen from Asymptomatic Child, China. Emerg Infect Dis 2020. [Epub ahead of print].

81. Epidemiology Working Group for NCIP Epidemic Response, Chinese Center for Disease Control and Prevention. The epidemiological characteristics of an outbreak of 2019 novel coronavirus diseases (COVID-19) in China. Zhonghua Liu Xing Bing Xue Za Zhi 2020;41:145-51.

82. Zhang J, Dong X, Cao Y, et al. Clinical characteristics of 140 patients infected with SARS-CoV-2 in Wuhan, China. Allergy 2020. [Epub ahead of print].

83. Li YY, Wang WN, Lei Y, et al. Comparison of the clinical characteristics between RNA positive and negative patients clinically diagnosed with 2019 novel coronavirus pneumonia. Zhonghua Jie He He Hu Xi Za Zhi 2020;43:E023.

84. Chen L, Liu HG, Liu W, et al. Analysis of clinical features of 29 patients with 2019 novel coronavirus pneumonia. Zhonghua Jie He He Hu Xi Za Zhi 2020;43:203-8.

85. Huang C, Wang Y, Li X, et al. Clinical features of patients infected with 2019 novel coronavirus in Wuhan, China. Lancet 2020;395:497-506. 
86. Chen N, Zhou M, Dong X, et al. Epidemiological and clinical characteristics of 99 cases of 2019 novel coronavirus pneumonia in Wuhan, China: a descriptive study. Lancet 2020;395:507-13.

87. Wang D, Hu B, Hu C, et al. Clinical Characteristics of 138 Hospitalized Patients With 2019 Novel CoronavirusInfected Pneumonia in Wuhan, China. JAMA 2020. [Epub ahead of print].

88. Hu Z, Song C, Xu C, et al. Clinical characteristics of 24 asymptomatic infections with COVID-19 screened among close contacts in Nanjing, China. Sci China Life Sci 2020;63:706-11.

89. Pediatric Branch of Hubei Medical Association, Pediatric Branch of Wuhan Medical Association, Pediatric Medical Quality Control Center of Hubei. Recommendation for the diagnosis and treatment of novel coronavirus infection in children in Hubei (Trial version 1). Zhongguo Dang Dai Er Ke Za Zhi 2020;22:96-9.

90. Chen Z, Fu J, Shu Q, et al. Diagnosis and treatment recommendation for pediatric COVID-19 (the second edition). Zhejiang Da Xue Xue Bao Yi Xue Ban 2020;49:139-46.

91. Xu H, Luo Zh, Xu F. Diagnosis and treatment of the 2019 novel coronavirus infection in children. (Trial version 2 of Children's Hospital of Chongqing Medical University). Journal of Pediatric Pharmacy 2020. Available online: http://kns.cnki.net/kcms/detail/50.1156. R.20200226.1309.002.html

92. Wang M, Yue S. The programme for prevention and control of SARS-CoV-2 infection in neonates in Hunan Provence. China J Mod Med 2020:65-71.

93. Li ZZ, Shen KL, Wei XM, et al. Clinical analysis of pediatric SARS cases in Beijing. Zhonghua Er Ke Za Zhi 2003;41:574-7.

94. Memish ZA, Al-Tawfiq JA, Assiri A, et al. Middle East respiratory syndrome coronavirus disease in children. Pediatr Infect Dis J 2014;33:904-6.

Cite this article as: Wang Z, Zhou Q, Wang C, Shi Q, Lu S, Ma Y, Luo X, Xun Y, Li W, Baskota M, Yang Y, Zhai H, Fukuoka T, Ahn HS, Lee MS, Luo Z, Liu E, Chen Y; on behalf of COVID-19 Evidence and Recommendations Working Group. Clinical characteristics of children with COVID-19: a rapid review and meta-analysis. Ann Transl Med 2020;8(10):620. doi: 10.21037/atm-20-3302
95. Young BE, Ong SWX, Kalimuddin S, et al. Epidemiologic features and clinical course of patients infected with SARSCoV-2 in Singapore. JAMA 2020. [Epub ahead of print].

96. Ong SWX, Tan YK, Chia PY, et al. Air, surface environmental, and personal protective equipment contamination by severe acute respiratory syndrome coronavirus 2 (SARS-CoV-2) from a symptomatic patient. JAMA 2020. [Epub ahead of print].

97. Rodriguez-Morales AJ, Cardona-Ospina JA, GutiérrezOcampo E, et al. Clinical, laboratory and imaging features of COVID-19: A systematic review and meta-analysis. Travel Med Infect Dis 2020. [Epub ahead of print].

98. Pei Y, Liu W, Ismail BM, et al. COVID-19: Children comparison with adults based on the latest data. SSRN 2020. doi: 10.2139/ssrn.3550063.

99. Li LQ, Huang T, Wang YQ, et al. COVID-19 patients' clinical characteristics, discharge rate, and fatality rate of meta-analysis. J Med Virol 2020. [Epub ahead of print].

100. Qian K, Deng Y, Tai Y, et al. Clinical characteristics of 2019 novel infected coronavirus pneumonia: a systemic review and meta-analysis. medrxiv 2020.doi: 10.1101/2020.02.14.20021535

101. Sun P, Qie S, Liu Z, et al. Clinical characteristics of hospitalized patients with SARS-CoV-2 infection: a single arm meta-analysis. J Med Virol 2020. [Epub ahead of print].

102.Fang Z, Yi F, Wu K, et al. Clinical characteristics of coronavirus disease 2019 (COVID-19): an updated systematic review. medrxiv 2020. doi: 10.1101/2020.03.07.20032573.

103.Ludvigsson JF. Systematic review of COVID-19 in children shows milder cases and a better prognosis than adults. Acta Paediatr 2020;109:1088-95.

104. World Health Organization. WHO handbook for guideline development, 2nd ed. 2014. Available online: https://apps.who.int/iris/handle/10665/145714 


\section{Supplementary File I Search strategy}

\section{PubMed}

\#1 "Epidemiological Studies"[Title/Abstract]

\#2 "Epidemiologic* Study"[Title/Abstract]

\#3 "Epidemiological characteristics"[Title/Abstract]

\#4 "Clinical features"[Title/Abstract]

\#5 "Clinical characteristics"[Title/Abstract]

\#6 "Clinical Presentation"[Title/Abstract]

\#7 \#1-\#6/ OR

\#8 "COVID-19"[Supplementary Concept]

\#9 "Severe Acute Respiratory Syndrome Coronavirus

2"[Supplementary Concept]

\#10 "COVID-19"[Title/Abstract]

\#11 "SARS-COV-2"[Title/Abstract]

\#12 "Novel coronavirus" [Title/Abstract]

\#13 "2019-novel coronavirus" [Title/Abstract]

\#14 "coronavirus disease-19" [Title/Abstract]

\#15 "coronavirus disease 2019" [Title/Abstract]

\#16 "COVID19" [Title/Abstract]

\#17 "Novel CoV" [Title/Abstract]

\#18 "2019-nCoV" [Title/Abstract]

\#19 "2019-CoV" [Title/Abstract]

\#20 \#8-\#19/ OR

\#21 \#7 AND \#20

\section{EMBASE}

\#1 'COVID-19':ab,ti

\#2 'SARS-COV-2':ab,ti

\#3 'novel coronavirus':ab,ti

\#4 '2019-novel coronavirus':ab,ti

\#5 'coronavirus disease-19':ab,ti

\#6 'coronavirus disease 2019':ab,ti

\#7 'COVID19':ab,ti

\#8 'novel cov':ab,ti

\#9 '2019-ncov':ab,ti

\#10 '2019-cov':ab,ti

\#11 \#1-10/OR

\#12 'epidemiological studies':ab,ti

\#13 'epidemiologic* study':ab,ti

\#14 'epidemiological characteristics':ab,ti

\#15 'clinical feature'/exp

\#16 'clinical features':ab,ti

\#17 'clinical characteristics':ab,ti

\#18 'clinical presentation':ab,ti

\#19 \#12-18/OR

\#20 \#11 AND \#19
\#21 \#20 AND [medline]/lim

\#22 \#20 NOT \#21

\section{Web of Science}

\#1 TOPIC: "Epidemiological Studies"

\#2 TOPIC: "Epidemiologic* Study"

\#3 TOPIC: "Epidemiological characteristics"

\#4 TOPIC: "Clinical features"

\#5 TOPIC: "Clinical characteristics"

\#6 TOPIC: "Clinical Presentation"

\#7 \#1-6/OR

\#8 TOPIC: "COVID-19"

\#9 TOPIC: "SARS-COV-2"

\#10 TOPIC: "Novel coronavirus"

\#11 TOPIC: "2019-novel coronavirus"

\#12 TOPIC: "coronavirus disease-19"

\#13 TOPIC: "coronavirus disease 2019"

\#14 TOPIC: "COVID19"

\#15 TOPIC: "Novel CoV"

\#16 TOPIC: "2019-nCoV"

\#17 TOPIC: "2019-CoV"

\#18 \#8-17/ OR

\#19 \#7 AND \#18

\section{Cochrane}

\#1 "COVID-19":ti,ab,kw

\#2 "SARS-COV-2":ti,ab,kw

\#3 "Novel coronavirus":ti,ab,kw

\#4 "2019-novel coronavirus" :ti,ab,kw

\#5 "Novel CoV" :ti,ab,kw

\#6 "2019-nCoV" :ti,ab,kw

\#7 "coronavirus disease-19" :ti,ab,kw

\#8 "coronavirus disease 2019" :ti,ab,kw

\#9 "COVID19" :ti,ab,kw

\#10 \#1-9/OR

\#11 "Epidemiological Studies":ti,ab,kw

\#12 "Epidemiologic* Study":ti,ab,kw

\#13 "Epidemiological characteristics":ti,ab,kw

\#14 "Clinical features":ti,ab,kw

\#15 "Clinical characteristics":ti,ab,kw

\#16 "Clinical Presentation":ti,ab,kw

\#17 \#11-16/ OR

\#18 \#10 AND \#17

\section{CBM}


\#1 "新型冠状病毒"[常用字段:智能]

\#2 "COVID-19"[常用字段:智能]

\#3 "COVID 19"[常用字段:智能]

\#4 "2019-nCoV"[常用字段:智能]

\#5 "2019-CoV"[常用字段:智能]

\#6 "SARS-CoV-2"[常用字段:智能]

\#7 \#1-6/OR

\#8 "流行病学"[中文标题:智能]

\#9 "临床表现"[中文标题:智能]

\#10 "临床特征"[中文标题:智能]

\#11 "临床特点"[中文标题:智能]

\#12 \#8-11/ OR

\#13 \#7 AND \#12

\section{WanFang}

\#1 "新型冠状病毒"[主题]

\#2 "COVID-19"[主题]

\#3 "COVID 19"[主题]

\#4 "2019-nCoV"[主题]

\#5 "2019-CoV"[主题]

\#6 "SARS-CoV-2"[主题]

\#7 \#1-\#6/ OR
\#8 "流行病学"[题名]

\#9 "临床特点"[题名]

\#10 "临床特征"[题名]

\#11 "临床表现"[题名]

\#12 \#8-11/ OR

\#13 \#7 AND \#12 
Supplementary File II Risk of bias

Table A National Institute for Health and $\mathrm{C}$ re

\begin{tabular}{|c|c|c|c|c|c|c|c|c|c|}
\hline Author & $\begin{array}{l}\text { 1. Case series collected in } \\
\text { more than one centre, i.e., } \\
\text { multi-centre study }\end{array}$ & $\begin{array}{l}\text { 2. Is the hypothesis/aim/ } \\
\text { objective of the study clearly } \\
\text { described? }\end{array}$ & $\begin{array}{l}\text { 3. Are the inclusion and } \\
\text { exclusion criteria (case } \\
\text { definition) clearly reported? }\end{array}$ & $\begin{array}{l}\text { 4. Is there a clear definition of } \\
\text { the outcomes reported? }\end{array}$ & $\begin{array}{l}\text { 5. Were data collected } \\
\text { prospectively? }\end{array}$ & $\begin{array}{l}\text { 6. Is there an explicit } \\
\text { statement that patients were } \\
\text { recruited consecutively? }\end{array}$ & $\begin{array}{l}\text { 7. Are the main findings of the } \\
\text { study clearly described? }\end{array}$ & $\begin{array}{l}\text { 8. Are outcomes stratified? } \\
\text { (e.g., by disease stage, } \\
\text { abnormal test results, patient } \\
\text { characteristics) }\end{array}$ & $\begin{array}{l}\text { Total } \\
\text { Score }\end{array}$ \\
\hline Deng 2020, (32) & No & Yes & Yes & No & Yes & No & Yes & No & 4 \\
\hline Cai 2020, (33) & No & Yes & Yes & No & Yes & No & Yes & No & 4 \\
\hline Zhang 2020, (34) & No & Yes & Yes & No & Yes & No & Yes & No & 4 \\
\hline Wei 2020, (35) & Yes & Yes & Yes & Yes & No & No & Yes & No & 5 \\
\hline Chen 2020, (36) & No & Yes & Yes & Yes & Yes & No & Yes & No & 5 \\
\hline Zeng 2020, (37) & No & Yes & Yes & Yes & Yes & No & Yes & No & 5 \\
\hline Wang 2020, (39) & No & Yes & Yes & No & Yes & No & Yes & No & 4 \\
\hline Quan 2020, (40) & No & Yes & Yes & No & Yes & No & Yes & No & 4 \\
\hline Xiong 2020, (41) & No & Yes & Yes & No & Yes & No & Yes & No & 4 \\
\hline Cai 2020, (42) & Yes & Yes & Yes & No & Yes & No & Yes & No & 5 \\
\hline Wang 2020, (43) & Yes & Yes & Yes & Yes & No & No & Yes & No & 5 \\
\hline Tang 2020, (44) & No & Yes & Yes & Yes & No & No & Yes & No & 4 \\
\hline Liu 2020, (45) & Yes & Yes & Yes & Yes & No & No & Yes & Yes & 6 \\
\hline Lu 2020, (46) & No & Yes & Yes & No & Yes & No & Yes & Yes & 5 \\
\hline Li 2020, (49) & Yes & Yes & Yes & Yes & No & No & Yes & No & 5 \\
\hline Zhang 2020, (50) & No & Yes & Yes & Yes & No & No & Yes & No & 4 \\
\hline Zhang 2020, (51) & No & Yes & No & No & No & No & Yes & Yes & 3 \\
\hline Liu 2020, (52) & No & Yes & No & No & No & No & Yes & Yes & 3 \\
\hline Xiao 2020, (53) & No & Yes & Yes & Yes & No & No & Yes & Yes & 5 \\
\hline Xu 2020, (54) & Yes & Yes & Yes & Yes & No & No & Yes & Yes & 5 \\
\hline Chan 2020, (55) & No & Yes & Yes & Yes & No & Yes & Yes & Yes & 6 \\
\hline Kam 2020, (56) & No & Yes & No & Yes & No & No & Yes & Yes & 4 \\
\hline Park 2020, (57) & No & Yes & No & No & No & No & Yes & Yes & 3 \\
\hline Du 2020, (58) & Yes & Yes & Yes & Yes & No & Yes & Yes & Yes & 7 \\
\hline Liu 2020, (59) & Yes & Yes & No & Yes & No & No & Yes & Yes & 5 \\
\hline Wang 2020, (60) & No & Yes & No & Yes & No & No & Yes & Yes & 4 \\
\hline Rahimzadeh 2020, (61) & Yes & Yes & No & No & No & No & Yes & Yes & 4 \\
\hline Ji 2020, (62) & No & Yes & No & Yes & No & No & Yes & Yes & 4 \\
\hline Xu 2020, (63) & No & Yes & Yes & No & No & No & Yes & Yes & 4 \\
\hline Xia 2020, (64) & No & Yes & Yes & Yes & No & No & Yes & No & 4 \\
\hline Dong 2020, (65) & Yes & Yes & Yes & Yes & No & No & Yes & Yes & 6 \\
\hline Liu 2020, (68) & No & Yes & Yes & Yes & No & No & Yes & Yes & 5 \\
\hline MA 2020, (69) & No & Yes & Yes & Yes & No & No & Yes & Yes & 5 \\
\hline Qian 2020, (70) & No & Yes & No & No & No & No & Yes & Yes & 3 \\
\hline Zhang 2020, (72) & Yes & Yes & Yes & Yes & No & No & Yes & Yes & 6 \\
\hline Sun 2020, (73) & No & Yes & Yes & Yes & No & No & Yes & No & 4 \\
\hline Dong 2020, (74) & Yes & Yes & No & Yes & No & No & Yes & Yes & 5 \\
\hline Wu 2020, (75) & Yes & Yes & Yes & Yes & No & No & Yes & No & 5 \\
\hline Su 2020, (76) & No & Yes & Yes & Yes & No & No & Yes & Yes & 5 \\
\hline Le 2020, (77) & No & Yes & No & No & No & No & Yes & Yes & 3 \\
\hline Zhong 2020, (78) & No & Yes & Yes & Yes & No & No & Yes & Yes & 5 \\
\hline Liu 2020, (79) & Yes & Yes & Yes & Yes & No & No & Yes & Yes & 6 \\
\hline Tang 2020, (80) & No & Yes & No & No & No & No & Yes & Yes & 3 \\
\hline
\end{tabular}


Table B Newcastle-Ottawa Scale

\begin{tabular}{|c|c|c|c|c|c|c|c|c|}
\hline \multirow[b]{2}{*}{ Author } & \multicolumn{4}{|c|}{ SELECTION } & \multirow{2}{*}{$\begin{array}{l}\text { COMPARABILITY } \\
\text { 1) Comparability of } \\
\text { Cohorts on the Basis of } \\
\text { the Design or Analysis }\end{array}$} & \multicolumn{3}{|c|}{ OUTCOME } \\
\hline & $\begin{array}{l}\text { 1) } \\
\text { Representativeness } \\
\text { of the Exposed } \\
\text { Cohort }\end{array}$ & $\begin{array}{l}\text { 2) Selection of } \\
\text { the Non-Exposed } \\
\text { Cohort }\end{array}$ & $\begin{array}{l}\text { 3) } \\
\text { Ascertainment } \\
\text { of Exposure }\end{array}$ & $\begin{array}{l}\text { 4) Demonstration That } \\
\text { Outcome of Interest Was Not } \\
\text { Present at Start of Study }\end{array}$ & & $\begin{array}{l}\text { 1) Assessment } \\
\text { of Outcome }\end{array}$ & $\begin{array}{l}\text { 2) Was Follow- } \\
\text { Up Long Enough } \\
\text { for Outcomes to } \\
\text { Occur }\end{array}$ & $\begin{array}{l}\text { 3) Adequacy of } \\
\text { Follow Up of } \\
\text { Cohorts }\end{array}$ \\
\hline Qiu 2020, (71) & th & & 㶦 & 论 & & 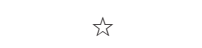 & & \\
\hline
\end{tabular}

it means one star, which have been explained in the part of the "Risk of bias assessment". 


\section{Supplementary File III GRADE evidence profile}

Table C Symptoms and imaging findings

\begin{tabular}{|c|c|c|c|c|c|c|c|c|c|}
\hline \multirow[b]{2}{*}{ No. of studies } & \multicolumn{5}{|c|}{ Certainty assessment } & \multicolumn{2}{|c|}{ No. of patients } & \multirow{2}{*}{$\begin{array}{l}\text { Effect value } \\
(95 \% \mathrm{Cl})\end{array}$} & \multirow[b]{2}{*}{ Certainty } \\
\hline & Risk of bias & Inconsistency & Indirectness & Imprecision & $\begin{array}{c}\text { Other } \\
\text { considerations }\end{array}$ & Total & Event & & \\
\hline \multicolumn{10}{|l|}{ The overall symptoms } \\
\hline No symptom, (17) & Serious $^{1}$ & Serious $^{2}$ & Not serious & Not serious & None & 1,396 & 218 & $19 \%(14 \%, 23 \%)$ & $\begin{array}{c}\oplus \oplus \bigcirc \bigcirc \\
\text { Low }\end{array}$ \\
\hline Mild symptom, (19) & Serious $^{1}$ & Serious $^{2}$ & Not serious & Not serious & None & 1,540 & 1,396 & $94 \%(90 \%, 98 \%)$ & $\begin{array}{c}\oplus \oplus \bigcirc \bigcirc \\
\text { Low }\end{array}$ \\
\hline Severe symptom, (19) & Serious $^{1}$ & Not serious & Not serious & Not serious & None & 1,525 & 49 & $3 \%(2 \%, 4 \%)$ & $\begin{array}{l}\oplus \oplus \oplus \bigcirc \\
\text { Moderate }\end{array}$ \\
\hline $\begin{array}{l}\text { More than one sign } \\
\text { or symptom, (15) }\end{array}$ & Serious $^{1}$ & Serious $^{2}$ & Not serious & Not serious & None & 281 & 104 & $35 \%(21 \%, 48 \%)$ & $\begin{array}{c}\oplus \oplus \bigcirc \bigcirc \\
\text { Low }\end{array}$ \\
\hline \multicolumn{10}{|l|}{ Specific symptoms } \\
\hline Fever, (22) & Serious $^{1}$ & Serious $^{2}$ & Not serious & Not serious & None & 890 & 418 & $48 \%(39 \%, 56 \%)$ & $\begin{array}{c}\oplus \oplus \bigcirc \bigcirc \\
\text { Low }\end{array}$ \\
\hline Cough, (20) & Serious $^{1}$ & Serious $^{2}$ & Not serious & Not serious & None & 766 & 352 & $39 \%(30 \%, 48 \%)$ & $\begin{array}{c}\oplus \oplus \bigcirc \bigcirc \\
\text { Low }\end{array}$ \\
\hline Fever and cough, (7) & Serious $^{1}$ & Serious $^{2}$ & Not serious & Not serious & None & 203 & 76 & $30 \%(18 \%, 42 \%)$ & $\begin{array}{c}\oplus \oplus \bigcirc \bigcirc \\
\text { Low }\end{array}$ \\
\hline Sputum production, (4) & Serious $^{1}$ & Serious $^{2}$ & Not serious & Serious $^{3}$ & None & 292 & 92 & $19 \%(0 \%, 44 \%)$ & $\begin{array}{l}\oplus \bigcirc \bigcirc \bigcirc \\
\text { Very low }\end{array}$ \\
\hline Rhinorrhoea, (9) & Serious $^{1}$ & Not serious & Not serious & Not serious & None & 380 & 37 & $9 \%(6 \%, 12 \%)$ & $\begin{array}{l}\oplus \oplus \oplus \bigcirc \\
\text { Moderate }\end{array}$ \\
\hline $\begin{array}{l}\text { Shortness of } \\
\text { breath/dyspnoea, (6) }\end{array}$ & Serious $^{1}$ & Serious $^{2}$ & Not serious & Not serious & None & 343 & 64 & $9 \%(0 \%, 19 \%)$ & $\begin{array}{c}\oplus \oplus \bigcirc \bigcirc \\
\text { Low }\end{array}$ \\
\hline Myalgia or fatigue, (10) & Serious $^{1}$ & Serious $^{2}$ & Not serious & Not serious & None & 524 & 49 & $8 \%(5 \%, 12 \%)$ & $\begin{array}{c}\oplus \oplus \bigcirc \bigcirc \\
\text { Low }\end{array}$ \\
\hline Diarrhoea, (10) & Serious $^{1}$ & Not serious & Not serious & Not serious & None & 528 & 42 & $7 \%(5 \%, 9 \%)$ & $\begin{array}{l}\oplus \oplus \oplus \bigcirc \\
\text { Moderate }\end{array}$ \\
\hline Nausea or vomiting, (8) & Serious $^{1}$ & Not serious & Not serious & Not serious & None & 430 & 27 & $6 \%(4 \%, 9 \%)$ & $\begin{array}{l}\oplus \oplus \oplus \bigcirc \\
\text { Moderate }\end{array}$ \\
\hline Nasal obstruction, (6) & Serious $^{1}$ & Not serious & Not serious & Not serious & None & 262 & 19 & $6 \%(3 \%, 9 \%)$ & $\begin{array}{l}\oplus \oplus \oplus \bigcirc \\
\text { Moderate }\end{array}$ \\
\hline Sore throat, (10) & Serious $^{1}$ & Not serious & Not serious & Not serious & None & 244 & 20 & $6 \%(2 \%, 10 \%)$ & $\begin{array}{l}\oplus \oplus \oplus \bigcirc \\
\text { Moderate }\end{array}$ \\
\hline Headache, (7) & Serious $^{1}$ & Not serious & Not serious & Not serious & None & 289 & 14 & $4 \%(1 \%, 6 \%)$ & $\begin{array}{l}\oplus \oplus \oplus \bigcirc \\
\text { Moderate }\end{array}$ \\
\hline \multicolumn{10}{|l|}{ Imaging findings } \\
\hline Abnormal, (18) & Serious $^{1}$ & Serious $^{2}$ & Not serious & Not serious & None & 674 & 447 & $66 \%(55 \%, 77 \%)$ & $\begin{array}{c}\oplus \oplus \bigcirc \bigcirc \\
\text { Low }\end{array}$ \\
\hline Unilateral pneumonia, (10) & Serious $^{1}$ & Serious $^{2}$ & Not serious & Not serious & None & 347 & 111 & $31 \%(20 \%, 43 \%)$ & $\begin{array}{c}\oplus \oplus \bigcirc \bigcirc \\
\text { Low }\end{array}$ \\
\hline Bilateral pneumonia, (13) & Serious $^{1}$ & Serious $^{2}$ & Not serious & Not serious & None & 597 & 146 & $28 \%(20 \%, 36 \%)$ & $\begin{array}{c}\oplus \oplus \bigcirc \bigcirc \\
\text { Low }\end{array}$ \\
\hline Ground-glass opacity, (14) & Serious $^{1}$ & Serious $^{2}$ & Not serious & Not serious & None & 727 & 246 & $35 \%(26 \%, 44 \%)$ & $\begin{array}{c}\oplus \oplus \bigcirc \bigcirc \\
\text { Low }\end{array}$ \\
\hline
\end{tabular}


Table D Laboratory results

\begin{tabular}{|c|c|c|c|c|c|c|c|c|}
\hline \multirow[b]{2}{*}{ No. of studies } & \multicolumn{5}{|c|}{ Certainty assessment } & \multirow{2}{*}{$\frac{\text { No. of patients }}{\text { Total }}$} & \multirow{2}{*}{$\begin{array}{l}\text { Effect value } \\
(95 \% \mathrm{Cl})\end{array}$} & \multirow[b]{2}{*}{ Certainty } \\
\hline & Risk of bias & Inconsistency & Indirectness & Imprecision & $\begin{array}{c}\text { Other } \\
\text { considerations }\end{array}$ & & & \\
\hline \multicolumn{9}{|l|}{ Blood routine values } \\
\hline Leucocytes (×109/L), (11) & Serious $^{1}$ & Not serious & Not serious & Not serious & None & 465 & $6.60(6.19,7.01)$ & $\begin{array}{l}\oplus \oplus \oplus \bigcirc \bigcirc \\
\text { Moderate }\end{array}$ \\
\hline Lymphocytes (×10\%/L), (8) & Serious $^{1}$ & Serious $^{2}$ & Not serious & Not serious & None & 356 & $2.76(2.47,3.05)$ & $\begin{array}{l}\oplus \oplus \bigcirc \bigcirc \\
\text { Low }\end{array}$ \\
\hline Neutrophils (×109/L), (5) & Serious $^{1}$ & Serious $^{2}$ & Not serious & Not serious & None & 236 & $2.70(2.10,3.31)$ & $\begin{array}{l}\oplus \oplus \bigcirc \bigcirc \\
\text { Low }\end{array}$ \\
\hline Platelets $\left(\times 10^{9} / L\right),(6)$ & Serious ${ }^{1}$ & Serious $^{2}$ & Not serious & Not serious & None & 133 & $257.09(251.06,263.13)$ & $\begin{array}{l}\oplus \oplus \bigcirc \bigcirc \\
\text { Low }\end{array}$ \\
\hline Haemoglobin (g/L), (7) & Serious ${ }^{1}$ & Serious $^{2}$ & Not serious & Not serious & None & 304 & $127.61(123.80,131.41)$ & $\begin{array}{l}\oplus \oplus \bigcirc \bigcirc \\
\text { Low }\end{array}$ \\
\hline \multicolumn{9}{|l|}{ Blood biochemistry } \\
\hline Albumin (g/L), (2) & Serious $^{1}$ & Not serious & Not serious & Not serious & None & 41 & $45.30(45.13,45.47)$ & $\begin{array}{l}\oplus \oplus \oplus \bigcirc \\
\text { Moderate }\end{array}$ \\
\hline Alanine aminotransferase (U/L), (8) & Serious $^{1}$ & Serious $^{2}$ & Not serious & Serious $^{3}$ & None & 306 & $20.46(14.51,26.41)$ & $\begin{array}{l}\oplus \bigcirc \bigcirc \bigcirc \\
\text { Very low }\end{array}$ \\
\hline Aspartate aminotransferase (U/L), (7) & Serious $^{1}$ & Serious $^{2}$ & Not serious & Not serious & None & 281 & $32.04(30.25,33.83)$ & $\begin{array}{l}\oplus \oplus \bigcirc \bigcirc \\
\text { Low }\end{array}$ \\
\hline Total bilirubin ( $\mu \mathrm{mol} / \mathrm{L}),(2)$ & Serious $^{1}$ & Serious $^{2}$ & Not serious & Serious $^{3}$ & None & 41 & $8.14(1.45,14.82)$ & $\begin{array}{l}\oplus \bigcirc \bigcirc \bigcirc \\
\text { Very low }\end{array}$ \\
\hline Blood urea nitrogen (mmol/L), (5) & Serious $^{1}$ & Not serious & Not serious & Not serious & None & 240 & $3.81(3.43,4.18)$ & $\begin{array}{l}\oplus \oplus \oplus \bigcirc \\
\text { Moderate }\end{array}$ \\
\hline Creatinine ( $\mu \mathrm{mol} / \mathrm{L}),(5)$ & Serious ${ }^{1}$ & Serious $^{2}$ & Not serious & Serious $^{3}$ & None & 240 & $41.60(32.98,50.22)$ & $\begin{array}{l}\oplus \bigcirc \bigcirc \bigcirc \\
\text { Very low }\end{array}$ \\
\hline Creatine kinase (U/L), (3) & Serious $^{1}$ & Serious $^{2}$ & Not serious & Not serious & None & 59 & $104.37(95.66,113.08)$ & $\begin{array}{l}\oplus \oplus \bigcirc \bigcirc \\
\text { Low }\end{array}$ \\
\hline Lactate dehydrogenase (U/L), (7) & Serious $^{1}$ & Serious $^{2}$ & Not serious & Serious $^{3}$ & None & 334 & $264.43(241.85,287.02)$ & $\begin{array}{l}\oplus \bigcirc \bigcirc \bigcirc \\
\text { Very low }\end{array}$ \\
\hline Myoglobin (ug/L), (2) & Serious $^{1}$ & Not serious & Not serious & Not serious & None & 23 & $15.33(11.18,19.48)$ & $\begin{array}{l}\oplus \oplus \oplus \bigcirc \\
\text { Moderate }\end{array}$ \\
\hline Procalcitonin (g/L), (7) & Serious $^{1}$ & Not serious & Not serious & Not serious & None & 398 & $0.06(0.00,0.16)$ & $\begin{array}{l}\oplus \oplus \oplus \bigcirc \\
\text { Moderate }\end{array}$ \\
\hline CRP (mg/L), (8) & Serious $^{1}$ & Serious $^{2}$ & Not serious & Not serious & None & 348 & $5.05(1.86,8.24)$ & $\begin{array}{l}\oplus \oplus \bigcirc \square \\
\text { Low }\end{array}$ \\
\hline \multicolumn{9}{|l|}{ Coagulation function } \\
\hline $\begin{array}{l}\text { Activated partial } \\
\text { thromboplastin time(s), (2) }\end{array}$ & Serious $^{1}$ & Serious $^{2}$ & Not serious & Serious $^{3}$ & None & 38 & $37.59(28.69,46.48)$ & $\begin{array}{l}\oplus \bigcirc \bigcirc \bigcirc \\
\text { Very low }\end{array}$ \\
\hline Prothrombin time(s), (4) & Serious $^{1}$ & Serious $^{2}$ & Not serious & Not serious & None & 223 & $12.25(11.30,13.20)$ & $\begin{array}{l}\oplus \oplus \bigcirc \bigcirc \\
\text { Low }\end{array}$ \\
\hline D-dimer (mg/L), (8) & Serious $^{1}$ & Not serious & Not serious & Not serious & None & 261 & $0.33(0.17,0.49)$ & $\begin{array}{l}\oplus \oplus \oplus \bigcirc \\
\text { Moderate }\end{array}$ \\
\hline
\end{tabular}

\section{Explanations}

1. downgrade one level: The risk of bias is high due to the limitations of study design.

2. downgrade one level: Heterogeneity of data synthesis results, $I^{2}>50 \%$.

3. downgrade one level: Sample size is less than optimal information sample (OIS)

4. upgrade two levels: Large magnitude of effect, $R R>5$.

5. Outcome (number of studies) 
Supplementary File IV Case report summary

Table E Symptom

Deng 2020, (32) \begin{tabular}{ccc} 
Number & Mild symptom & Severe \\
\hline 2 & $2 / 2$
\end{tabular} Cai 2020, (33)

Zhang 2020, (34)

Zeng 2020, (37)

Wang 2020, (39)

Quan 2020, (40)

Xiong 2020, (41)

Than 2020,48

Zhang 2020, (51)

Liu 2020, (52)

Xiao 2020, (53)

Chan 2020, (55)

Park 2020, (57)

Liu 2020, (59)

Wang 2020, (60)

Ji 2020, (62)

Xing 2020, (66)
Qian, (70)

Qian, (70)

Sun, (73)

Dong, (74)

Le, (77)
Tang, (80)

$\begin{array}{cccc}\text { Severe symptom } & \text { Fever } & \text { Cough } & \text { Fever and } \\ 0 / 2 & 1 / 2 & 0 / 2 & 0 \\ 0 / 1 & 1 / 1 & 1 / 1 & 1 / 1 \\ 0 / 1 & 1 / 1 & 0 / 1 & 0 \\ 1 / 1 & 1 / 1 & 0 / 1 & 0 \\ 0 / 1 & 0 / 1 & 0 / 1 & 0 \\ 0 / 1 & 1 / 1 & 1 / 1 & 0 / 1 \\ 0 / 1 & 0 / 1 & 0 / 1 & 0 \\ 0 / 2 & 2 / 2 & 2 / 2 & 2 / 2 \\ 1 / 6 & 6 / 6 & 6 / 6 & 0 \\ 0 / 1 & 1 / 1 & 0 / 1 & 0 \\ 0 / 2 & 2 / 2 & 2 / 2 & 2 \\ 0 / 1 & 1 / 1 & 0 / 1 & 0 \\ 0 / 1 & 1 / 1 & 1 / 1 & 1 / 1 \\ 0 / 1 & 0 / 1 & 0 / 1 & 0 \\ 0 / 1 & 1 / 1 & 0 / 1 & 0 \\ 0 / 1 & 1 / 1 & 0 / 1 & 0 / 1 \\ 0 / 4 & 3 / 4 & 3 / 4 & 2 / 4 \\ 0 / 1 & 0 / 1 & 0 / 1 & 0 / 1 \\ 0 / 2 & 1 / 2 & 0 / 2 & 0 / 2 \\ 0 / 3 & 3 / 3 & 0 / 3 & 0 / 3 \\ 0 / 1 & 0 / 1 & 0 / 1 & 0 / 1 \\ 8 / 8 & 6 / 8 & 6 / 8 & 4 / 8 \\ 0 / 2 & 1 / 2 & 1 / 2 & 1 / 2 \\ 0 / 1 & 0 / 1 & 0 / 1 & 0 / 1 \\ 0 / 1 & 0 / 1 & 0 / 1 & 0 / 1\end{array}$

$\begin{array}{ccc} & & \\ 0 / 2 & 0 / 2 & 1 / 2 \\ 0 / 1 & 0 / 1 & 0 / 1 \\ 0 / 1 & 0 / 1 & 0 / 1 \\ 0 / 1 & 0 / 1 & 0 / 1 \\ 0 / 1 & 0 / 1 & 0 / 1 \\ 0 / 1 & 0 / 1 & 0 / 1 \\ 0 / 1 & 0 / 1 & 0 / 1 \\ 0 / 2 & 0 / 2 & 0 / 2 \\ 0 / 6 & 0 / 6 & 0 / 6 \\ 0 / 1 & 0 / 1 & 0 / 1 \\ 0 / 2 & 0 / 2 & 0 / 2 \\ 0 / 1 & 0 / 1 & 0 / 1 \\ 0 / 1 & 0 / 1 & 0 / 1 \\ 0 / 1 & 0 / 1 & 0 / 1 \\ 0 / 1 & 0 / 1 & 0 / 1 \\ 1 / 1 & 0 / 1 & 0 / 1 \\ 0 / 4 & 1 / 4 & 0 / 4 \\ 0 / 1 & 0 / 1 & 0 / 1 \\ 0 / 2 & 0 / 2 & 0 / 2 \\ 0 / 3 & 0 / 3 & 0 / 3 \\ 0 / 1 & 0 / 1 & 0 / 1 \\ 4 / 8 & 1 / 8 & 0 / 8 \\ 1 / 2 & 0 / 2 & 0 / 2 \\ 0 / 1 & 0 / 1 & 0 / 1 \\ 0 / 1 & 0 / 1 & 0 / 1 \\ & & \end{array}$

$1 / 2$
$0 / 1$
$0 / 1$
$0 / 1$
$0 / 1$
$0 / 1$
$0 / 1$
$0 / 2$
$0 / 6$
$0 / 1$
$0 / 2$
$0 / 1$
$0 / 1$
$0 / 1$
$0 / 1$
$0 / 1$
$0 / 4$
$0 / 1$
$0 / 2$
$0 / 3$
$0 / 1$
$0 / 8$
$0 / 2$
$0 / 1$
$0 / 1$

$0 / 2$
$0 / 1$
$0 / 1$
$0 / 1$
$0 / 1$
$0 / 1$
$0 / 1$
$0 / 2$
$1 / 6$
$0 / 1$
$0 / 2$
$0 / 1$
$0 / 1$
$0 / 1$
$0 / 1$
$0 / 1$
$0 / 4$
$0 / 1$
$0 / 2$
$0 / 3$
$0 / 1$
$8 / 8$
$0 / 2$
$0 / 1$
$0 / 1$

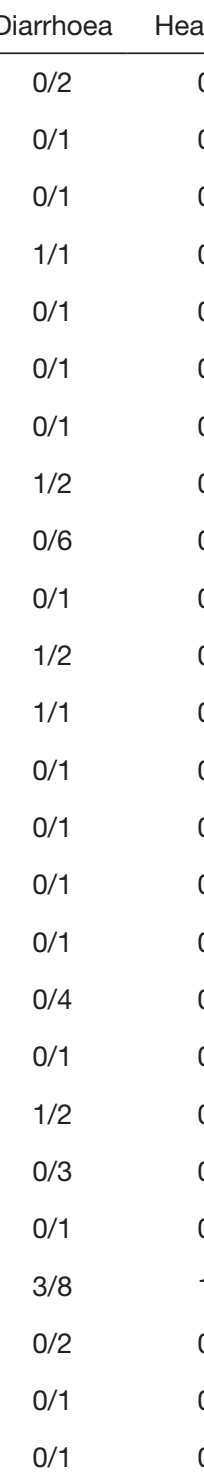

$0 / 2$
$0 / 1$
$0 / 1$
$0 / 1$
$0 / 1$
$0 / 1$
$0 / 1$
$0 / 2$
$0 / 6$
$0 / 1$
$0 / 2$
$0 / 1$
$0 / 1$
$0 / 1$
$0 / 1$
$0 / 1$
$0 / 4$
$0 / 1$
$0 / 2$
$0 / 3$
$0 / 1$
$0 / 8$
$0 / 2$
$1 / 1$
$0 / 1$

$$
\begin{aligned}
& \text { Rhinorho } \\
& 0 / 2 \\
& 0 / 1 \\
& 0 / 1 \\
& 0 / 1 \\
& 0 / 1 \\
& 0 / 1 \\
& 0 / 1 \\
& 1 / 2 \\
& 1 / 6 \\
& 0 / 1 \\
& 0 / 2 \\
& 0 / 1 \\
& 1 / 1 \\
& 0 / 1 \\
& 0 / 1 \\
& 0 / 1 \\
& 0 / 4 \\
& 0 / 1 \\
& 0 / 2 \\
& 0 / 3 \\
& 0 / 1 \\
& 0 / 8 \\
& 0 / 2 \\
& 1 / 1 \\
& 0 / 1
\end{aligned}
$$

Nausea or vom

\begin{tabular}{ccc}
\hline ea or vomiting & No symptom & More than one sign or symptom \\
\hline $0 / 2$ & $0 / 2$ & $0 / 2$
\end{tabular}

No symptom
$0 / 2$
$0 / 1$

$0 / 1$ 
Table F Imaging findings and family contact

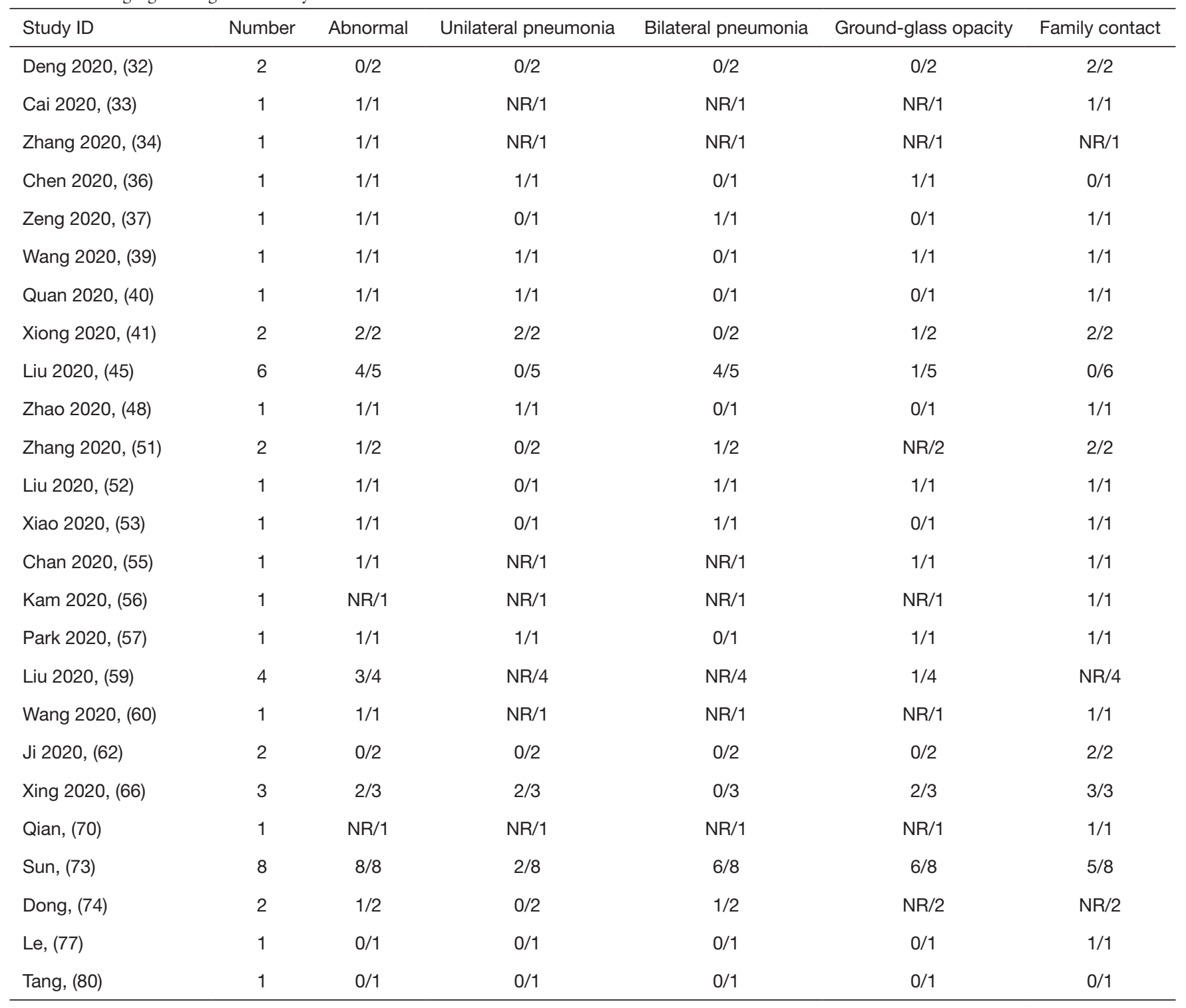

NR, not report. 
